\title{
Role of Directed van der Waals Bonded Interactions in the Determination of the Structures of Molecular Arsenate Solids
}

\author{
G. V. Gibbs, ${ }^{*}, \dagger$ A. F. Wallace,${ }^{\dagger}$ D. F. Cox,$\stackrel{+}{\dagger}$ P. M. Dove,${ }^{\dagger}$ R. T. Downs,${ }^{\S}$ N. L. Ross, ${ }^{\dagger}$ and \\ K. M. Rosso" \\ Department of Geosciences, and Department of Chemical Engineering, Virginia Tech, Blacksburg, Virginia \\ 24061, Department of Geosciences, University of Arizona, Tucson, Arizona 85721, and Chemical and Materials \\ Science Division and the W. R. Wiley Environmental Molecular Sciences Laboratory, Pacific Northwest \\ National Laboratory, Richland, Washington 99352
}

Received: August 28, 2008; Revised Manuscript Received: November 10, 2008

Bond paths, local energy density properties, and Laplacian, $L(\mathbf{r})=-\nabla^{2} \rho(\mathbf{r})$, composite isosurfaces of the electron density distributions were calculated for the intramolecular and intermolecular bonded interactions for molecular solids of $\mathrm{As}_{2} \mathrm{O}_{3}$ and $\mathrm{AsO}_{2}$ composition, an $\mathrm{As}_{2} \mathrm{O}_{5}$ crystal, a number of arsenate molecules, and the arsenic metalloid, arsenolamprite. The directed intermolecular van der Waals As-O, O-O, and As-As bonded interactions are believed to serve as mainstays between the individual molecules in each of the molecular solids. As $-\mathrm{O}$ bond paths between the bonded atoms connect Lewis base charge concentrations and Lewis acid charge depletion domains, whereas the $\mathrm{O}-\mathrm{O}$ and $\mathrm{As}-\mathrm{As}$ paths connect Lewis base pair and Lewis acid pair domains, respectively, giving rise to sets of intermolecular directed bond paths. The alignment of the directed bond paths results in the periodic structures adopted by the arsenates. The arrangements of the As atoms in the claudetite polymorphs of $\mathrm{As}_{2} \mathrm{O}_{3}$ and the As atoms in arsenolamprite are similar. Like the $\mathrm{As}_{2} \mathrm{O}_{3}$ polymorphs, arsenolamprite is a molecular solid connected by relatively weak As - As intermolecular directed van der Waals bond paths between the layers of stronger As-As intramolecular bonded interactions. The bond critical point and local energy density properties of the intermolecular As-As bonded interactions in arsenolamprite are comparable with the As-As interactions in claudetite I. As such, the structure of claudetite I can be viewed as a stuffed derivative of the arsenolamprite structure with $\mathrm{O}$ atoms between pairs of As atoms comprising the layers of the structure. The cubic structure adopted by the arsenolite polymorph can be understood in terms of sets of directed acid-base As-O and base-base $\mathrm{O}-\mathrm{O}$ pair domains and bond paths that radiate from the tetrahedral faces of its constituent molecules, serving as face-to-face key-lock mainstays in forming a periodic tetrahedral array of molecules rather than one based on some variant of close packing. The relatively dense structure and the corrugation of the layers in claudetite I can also be understood in terms of directed van der Waals As-O bonded interactions. Our study not only provides a new basis for understanding the crystal chemistry and the structures of the arsenates, but it also calls for a reappraisal of the concept of van der Waals bonded interactions, how the structures of molecular solids are viewed, and how the molecules in these solids are bonded in a periodic structure.

\section{Introduction}

It has been asserted that intermolecular van der Waals forces arise by dint of the correlation of dipole-dipole interactions among neighboring molecules. ${ }^{1}$ But, in a highly cited study of molecular forces, Feynman ${ }^{2}$ observed that van der Waals forces can be understood in terms of the buildup and the deformation of the electron density, ED, between the bonded nuclei of a pair of atoms in a molecule. He showed for the pair at a separation $R$, large compared with the radii of the atoms, that perturbation theory leads to the result that the ED distribution for each atom in the molecule is deformed from "central symmetry" with an induced dipole moment of the order $1 / R^{7}$ imposed on each. On the basis of his famous electrostatic theorem, Feynman concluded that it is not the fluctuating dipole-dipole interactions that result in the long-range van der

\footnotetext{
* Corresponding author. E-mail: gvgibbs@vt.edu.

Department of Geosciences, Virginia Tech.

* Department of Chemical Engineering, Virginia Tech.

$\S$ University of Arizona.

"Pacific Northwest National Laboratory.
}

Waals binding forces, but rather it is due to the net attraction of each of the nuclei for the deformed "distribution of its own electrons that gives the attractive $1 / R^{7}$ force". Using the virial theorem in a study of covalent binding, Slater ${ }^{3}$ has since stated "That there is no very fundamental distinction between the van der Waals binding and covalent binding", a statement that implies that van der Waals binding displays directional character. It also implies that intermolecular van der Waals binding among molecules is not distinct from intramolecular binding within the molecules other than the former are typically much weaker. In other words, it would appear that there is a continuum of binding interactions between van der Waals and covalent binding.

In a careful examination of the bonded and nonbonded interactions between molecules, Bader and MacDougall ${ }^{4}$ and more recently Bader et al. ${ }^{5}$ concluded that the buildup and the deformation of the ED is associated with the formation of local maxima and minima in the Laplacian, $L(\mathbf{r})=-\nabla^{2} \rho(\mathbf{r})$, of the ED distribution in the internuclear and the nonbonded regions together with the formation of directed bond paths linking the bonded atoms. These paths were asserted to serve as mainstays 
that govern how the molecules are arranged in space with respect to one another. The maxima define domains where $\rho(\mathbf{r})$ is locally charge-concentrated (a Lewis base nucleophile domain), whereas the minima define domains where $\rho(\mathbf{r})$ is locally charge-depleted (a Lewis acid electrophile domain). In an examination of the connection between these domains and the formation of directed bonded interactions and bond paths, Bader and MacDougall ${ }^{4}$ found that a Lewis base nucleophile domain of an atom of one molecule is commonly aligned with a Lewis acid electrophile domain of an atom of an adjacent molecule with a directed bond path connecting the two. ${ }^{5}$ This reaction corresponds to the combination of a domain of excess potential energy with one of excess kinetic energy to yield bonded pairs of atoms for which the virial theorem is satisfied for the pair. Pairs of Lewis base domains on adjacent molecules have also been observed to be aligned between two atoms with the domains likewise connected by an intermolecular directed bond path. ${ }^{6}$ Further, with the formation of a molecular solid, the constituent molecules are commonly aligned with a domain associated with an atom of one molecule aligned with a domain associated with an atom on an adjacent molecule with the pair of domains connected by directed intermolecular bond paths, so to speak, linking the two bonded atoms. ${ }^{5}$ Further, the alignment of Lewis base-acid pair domains and Lewis base-base pair domains and the associated directed bond paths are repeated over and over again with the generation of a periodic array of molecules, forming a molecular solid with parallel sets of directed intermolecular bond paths. ${ }^{6}$ Further, in the case of the alignment of the Lewis base-acid pair domains, the molecules are said to pack in a Fischer key-lock arrangement in which the Lewis domains of adjacent molecules are coupled together in a regular way with the formation of sets of directed parallel bond paths, resulting in a periodic array of molecules. As the $\rho\left(\mathbf{r}_{\mathrm{c}}\right)$ values for the Lewis base-acid pair domain bond paths are typically larger than the values for Lewis base-base and acid-acid pair domain bond paths, it has been asserted that the base-acid pair domain interactions play a larger role in determining the structure than the weaker base-base and acid-acid pair interactions. ${ }^{6}$ Typically, the intermolecular van der Waals bonded interactions and the associated directed parallel bond paths not only serve as mainstays for governing the spatial arrangement of molecules within the structure, but they also provide a basis for understanding the orientation of the molecules and the resulting periodic structure of the molecular solid.

With the Bader-MacDougall alignment strategy ${ }^{4}$ and directed bond paths, Tsirelson et al. ${ }^{6}$ demonstrated that the layered crystal structure adopted by solid molecular chlorine can be understood on the basis of the alignment of pairs of Lewis base-acid and base-base pair domains and their associated sets of parallel directed bond paths. The alignment of the Lewis base-acid pair domains are displayed in Figure 1 where representative interatomic $\mathrm{Cl}-\mathrm{Cl}$ directed bond paths (the blue lines labeled a and c) are determined by the deformation and local concentration of the ED associated with the formation of the base-acid pair domains. A third representative intermolecular directed bond path (the pink line labeled $b$ ) involves the alignment of a Lewis base-base pair nonbonded domains, an interaction that is asserted to be typically weaker than a Lewis base-acid pair interaction. ${ }^{7}$ In addition to being involved with an intramolecular directed bond path with the second $\mathrm{Cl}$ atom, each $\mathrm{Cl}$ atom of the $\mathrm{Cl}_{2}$ dimer is coupled with a number of additional intermolecular bond paths with the $\mathrm{Cl}$ atoms in the surrounding dimers, resulting in a layered orthorhombic crystal structure determined by the specifically directed parallel sets of directed intermo-

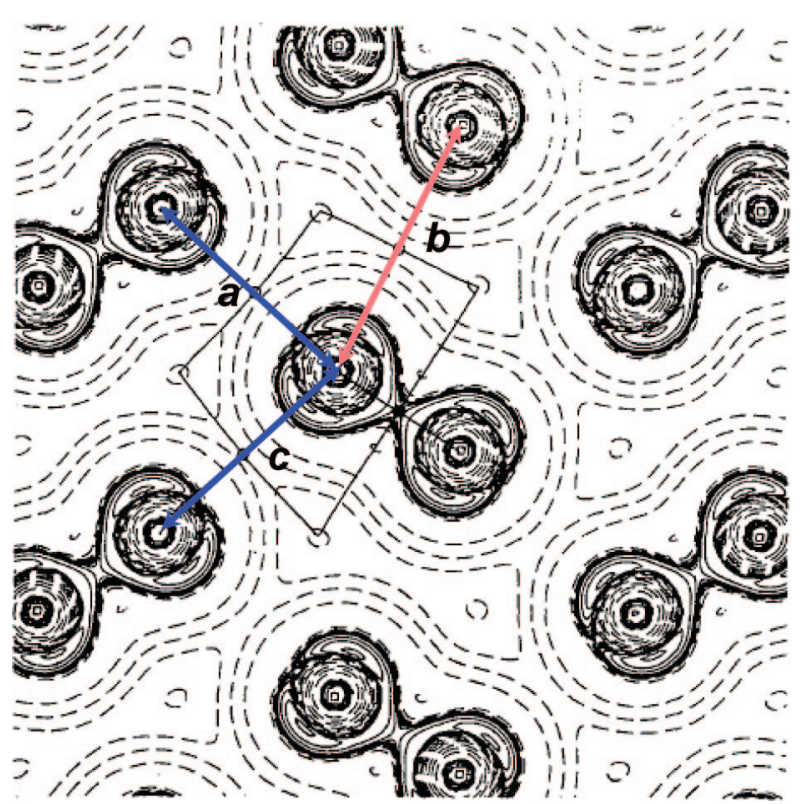

Figure 1. Laplacian, $L(\mathbf{r})=-\nabla^{2} \rho(\mathbf{r})$, level line contour map for a layer of $\mathrm{Cl}_{2}$ dimer molecules paralleling (100) in solid molecular chlorine. Each dimer displays four bilateral domains of nonbonded charge concentration (local maxima denoting Lewis base domains) in $L(\mathbf{r})$ on the sides of the molecule) and two domains of charge depletion (denoting Lewis acid domains) at the ends of the molecules (ref 6). The solid contour level lines denote positive values, and the dashed ones denote negative ones. The blue and pink lines that radiate from one of the $\mathrm{Cl}$ atoms of the central dimer delineate bond paths, and the small open circles along the paths denote the bond critical points labeled $\mathrm{a}, \mathrm{b}$, and c. There are three types of bond paths delineated: a representative intramolecular bond path displayed between the $\mathrm{Cl}$ atoms in the same dimer and two representative intermolecular bond paths, ones displayed between Lewis base-acid pairs (connected by bluecolored bond paths) with bond critical points a and c, and the other displayed between Lewis base-base pairs (connected by a pink-colored bond path) with bond critical point $b$.

lecular van der Waals $\mathrm{Cl}-\mathrm{Cl}$ bond paths that link the $\mathrm{Cl}$ atoms on adjacent molecules, either passing through a Lewis base-acid pair or a Lewis base-base pair domain (Figure 1).

As summarized by Tsirelson et al., ${ }^{6}$ molecular solid chlorine is not a structure that can be understood in terms of fluctuating dipole-dipole interactions and a nondirectional van der Waals potential but one that can be understood in terms of the alignment of base-acid and base-base pair domains and their associated directed bond paths that serve as mainstays for the resulting layer structure. Again, as they point out, a robust van der Waals model that includes quadrupole terms utterly fails to provide an understanding of the layered structure adopted by solid chlorine. ${ }^{7}$

In this report, the ED distributions, bond paths, bond critical point, bcp, and local density properties (Table 1 ) and composite Laplacian $L(\mathbf{r})$ isosurface maps were generated for the three $\mathrm{As}_{2} \mathrm{O}_{3}$ polymorphs, the arsenic metalloid, arsenolamprite, and related materials to establish whether the topological properties of the Laplacian distribution provide a basis for understanding the van der Waals long-range intermolecular bonded interactions and the structures and structural distortions that are adopted by the three $\mathrm{As}_{2} \mathrm{O}_{3}$ polymorphs in terms of the directed intermolecular bond paths. In addition to formation of Lewis acid-base and base-base directed bond paths, it will be of interest to see whether Lewis acid-acid directed bond paths are formed in the $\mathrm{As}_{2} \mathrm{O}_{3}$ polymorphs and particularly in arsenolamprite. The local energy density properties of the bond interactions were also calculated to establish the bond type, shared or closed- 
TABLE 1: Bond Critical Point and Local Energy Density Properties

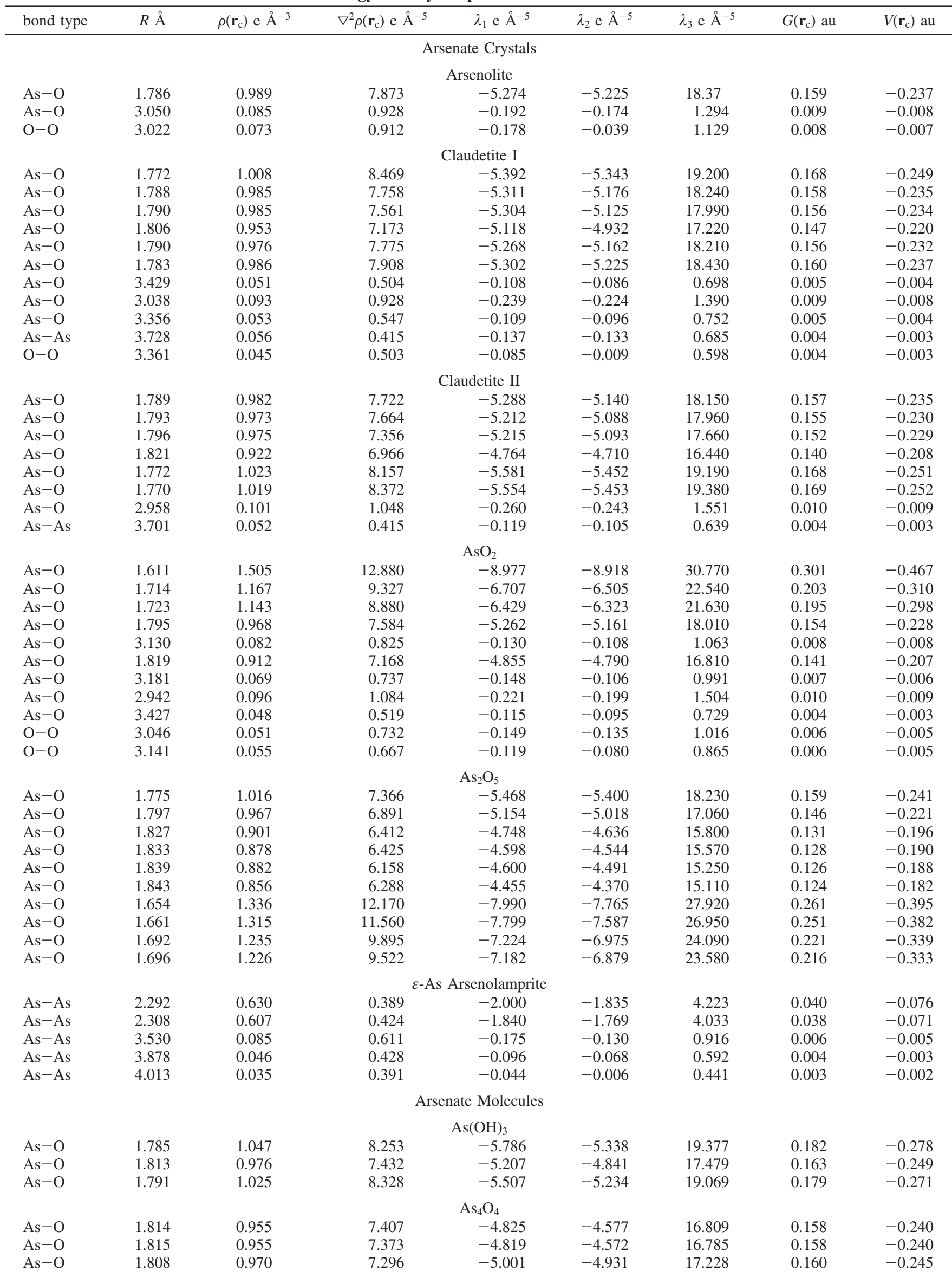


TABLE 1: Continued

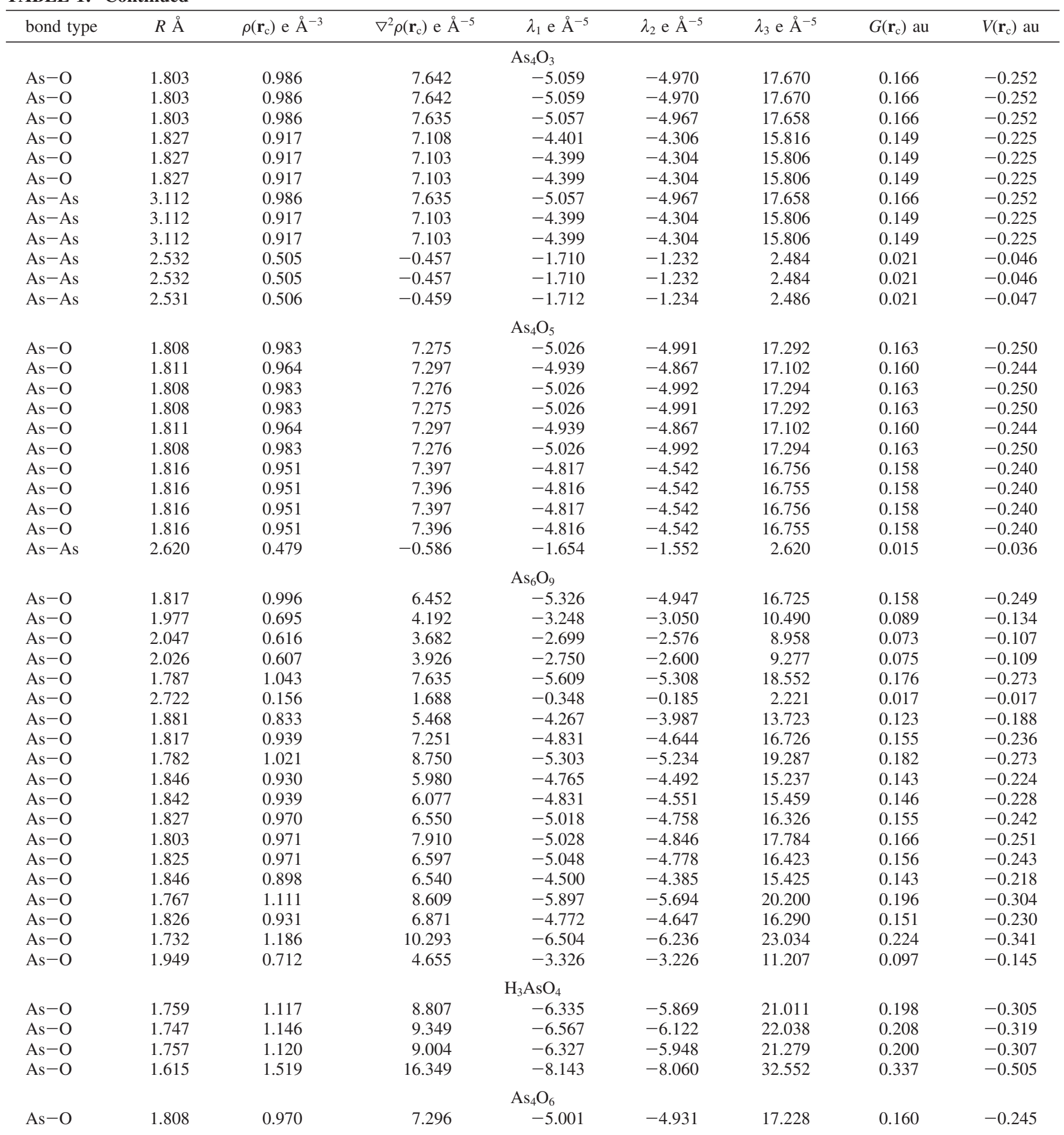

shell, in terms the local energy density values (Table 1). The ED distributions of the crystals were calculated with CRYSTAL98, ${ }^{8}$ and the bond critical point and the local energy density properties of the bonded interactions were calculated with TOPOND $^{9}$ (Table 1$)$. The composite $L(\mathbf{r})$ isosurface maps for the structures were generated at a grid level of 12 points per atomic unit, au, using a relatively robust $6-311 \mathrm{G}(2 \mathrm{~d} / \mathrm{p})$ basis set and the local spin density approximation as implemented in the Gaussian 03 suite of programs (e.g., Slater exchange with the Vosko-Wilk-Nuasair correlation functional). The isosurfaces of $L(\mathbf{r})$ generated in this study were displayed with the Visual Molecular Dynamic (VMD) software package. ${ }^{10}$

\section{van der Waals Bond Paths and Composite $L(\mathbf{r})$} Isosurface Maps

There are three known polymorphs of $\mathrm{As}_{2} \mathrm{O}_{3}$ : arsenolite, claudetite I, and claudetite II. Each is a molecular crystal consisting of molecules with corner-sharing $\mathrm{AsO}_{3}$ pyramidal units, bound by intermolecular van der Waals forces (Figure 2). ${ }^{11,12}$ Arsenolite consists of a cubic tetrahedral array of $\mathrm{As}_{4} \mathrm{O}_{6}$ molecules with rings of three pyramidal $\mathrm{AsO}_{3}$ units (Figure 2a), whereas the two claudetite polymorphs consist of corrugated molecular layers of the same composition with rings of six pyramidal units (Figure 2, parts b and c). In all three structures each $\mathrm{O}$ atom is bonded to two As atoms such that the bond 


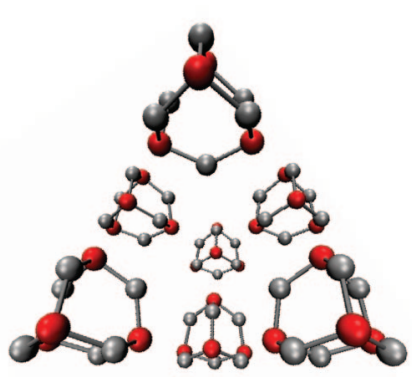

(a) Arsenolite $\mathrm{As}_{2} \mathrm{O}_{3}$

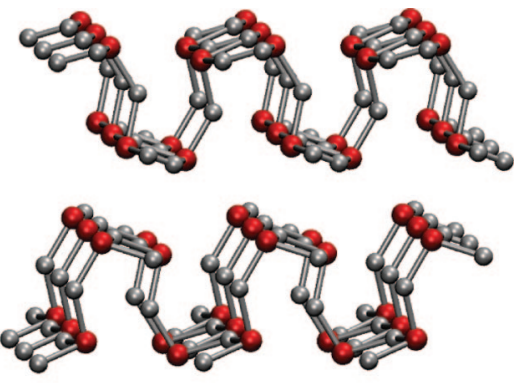

(b) Claudetite I $\mathrm{As}_{2} \mathrm{O}_{3}$

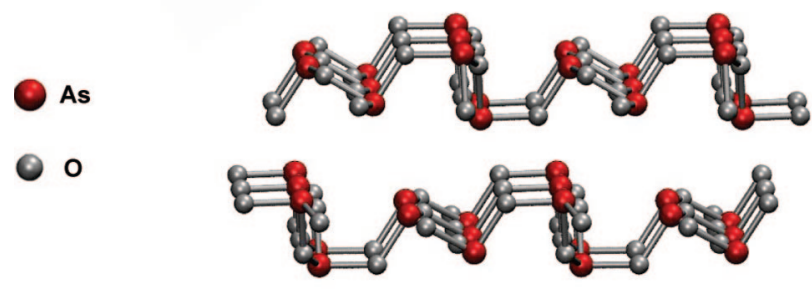

(c) Claudetite II $\mathrm{As}_{2} \mathrm{O}_{3}$

Figure 2. Pictures of the arsenate $\mathrm{As}_{2} \mathrm{O}_{3}$ structure types. (a) A picture of an array of seven equivalent $\mathrm{As}_{4} \mathrm{O}_{6}$ molecules of the arsenolite solid molecular structure view down $\sim[110]$; the silver spheres represent $\mathrm{O}$ and the red ones represent As atoms in $(\mathrm{a}-\mathrm{c})$ and in all of the remaining figures. The barycenter of the central molecule is at a fractional height of 0.125 , the ones at 2,6 , and 10 o'clock about the central molecule are at 0.375 , and the ones at 4, 8, and 12 o'clock are at 0.625. (b) A picture of two representative corrugated $\mathrm{As}_{2} \mathrm{O}_{3}$ molecular layers paralleling (010) composed of six-membered rings of corner-sharing $\mathrm{AsO}_{3}$ pyramidal units in the solid molecular claudetite I structure viewed edge-on down $\sim[100]$. (c) A picture of two representative layers of corrugated $\mathrm{As}_{2} \mathrm{O}_{3}$ molecular layers paralleling (001) consisting of six-membered rings of cornersharing $\mathrm{AsO}_{3}$ pyramidal units in the solid molecular claudetite structure II viewed edge-on down $\sim[010]$.

number sum reaching each $\mathrm{O}$ atom is two, the number of electrons required to impart a closed-shell configuration to the $\mathrm{O}$ atom. Arsenolite, synthesized by vapor deposition from vitreous $\mathrm{As}_{2} \mathrm{O}_{3}$, a glass with disordered array of three-membered rings, ${ }^{13}$ transforms reversibly when subjected to shear stress into the layer structure claudetite I at temperatures greater than 125 ${ }^{\circ} \mathrm{C} .{ }^{14}$ The layers in claudetite I are more highly corrugated (Figure 2b) than those in claudetite II (Figure 2c). Thermodynamic evidence indicates that claudetite $\mathrm{I}$ is stable at ambient conditions, transforming reversibly into the less dense claudetite II polymorph at temperatures greater than $240{ }^{\circ} \mathrm{C} . .^{15,16}$ Upon heating, claudetite I has been observed to disproportionate into the metalloid $\varepsilon$-As, the native arsenic mineral known as arsenolamprite, and $\mathrm{As}_{2} \mathrm{O}_{5}$ with a small fraction of atoms stuffing the voids in the structure. ${ }^{17}$ As demonstrated in this study, arsenolamprite is also a molecular solid consisting of layers of three-coordinated As atoms bound by relatively strong intramolecular bonded As-As interactions within the layers and relatively weak intermolecular van der Waals As-As interactions between the layers. As we will demonstrate, the arrangement of the As atoms in the claudetite polymorphs is comparable with that in arsenolamprite with $\mathrm{O}$ atoms in the claudetites stuffed among the As atoms forming layers of corner-sharing $\mathrm{AsO}_{3}$ pyramidal units linked together by relatively weak As-O, $\mathrm{As}-\mathrm{As}$, and $\mathrm{O}-\mathrm{O}$ intermolecular bonded interactions. Little is known about the properties of intramolecular As-O bonded interactions and even less is known about the long-range van der Waals intermolecular bonded interactions that bind the molecules in the three $\mathrm{As}_{2} \mathrm{O}_{3}$ polymorphs and arsenolamprite into molecular solids. This study was undertaken with the goal of clarifying and evaluating the properties of the intramolecular and particularly the intermolecular van der Waals bonded interactions in these materials in terms of their bond paths, the directed bond paths, the topology of their ED distributions, and their local energy density properties.

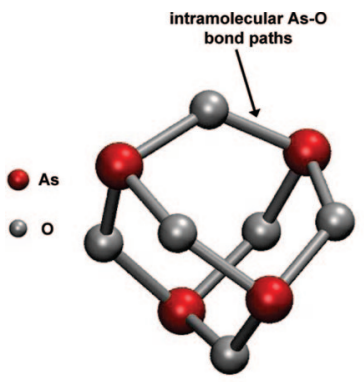

(a)

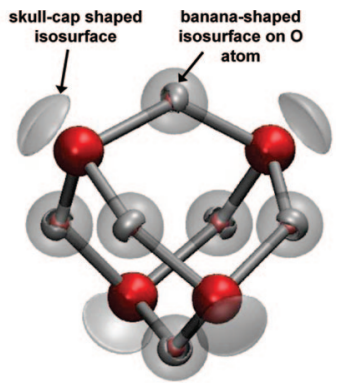

(b)
Figure 3. (a) Picture of the $\mathrm{As}_{4} \mathrm{O}_{6}$ molecule with the As atoms represented by red spheres and the $\mathrm{O}$ atoms represented by silver ones and (b) an $L(\mathbf{r})$ isosurface map for the molecule displaying a bananashaped silver-colored isosurface (representing a Lewis base domain where the ED is locally concentrated) located on each $\mathrm{O}$ atom on the reflex side of each As-O-As angle with an isosurface level line value of +12 au and spherical red-colored isosurfaces (representing a Lewis acid domain where the ED is locally depleted) calculated at the -22 au level, one located on the interior of the $\mathrm{O}$ atoms enclosed in part by the banana-shaped isosurface and the other enclosing the As atoms. A skullcap-shaped isosurface generated at the +0.01 au level caps each As.

Arsenolite. The structure of the $\mathrm{As}_{4} \mathrm{O}_{6}$ molecule $\left(T_{d}\right.$ point symmetry type) in arsenolite can be derived from the adamantine $\mathrm{C}_{10} \mathrm{H}_{16}$ molecule by removing the $16 \mathrm{H}$ atoms and replacing the 10 carbon atoms with 4 As and $6 \mathrm{O}$ atoms in perfect alternation within the molecule (Figure $3 \mathrm{a}$ ). The experimental As $-\mathrm{O}$ bond lengths, $R(\mathrm{As}-\mathrm{O})$, are $1.79 \AA$, and the $\mathrm{O}-\mathrm{As}-\mathrm{O}$ and As-O-As angles are $98.4^{\circ}$ and $128.7^{\circ}$, respectively. ${ }^{11}$ The distance between nearest-neighbor As atoms is $3.22 \AA$, and that between nearest-neighbor $\mathrm{O}$ atoms is $2.70 \AA$. The distance between each As atom and the barycenter, denoted $\mathrm{B}$, of the molecule $^{18}$ is $R(\mathrm{As}-\mathrm{B})=1.97 \AA$, and that between each $\mathrm{O}$ atom and $\mathrm{B}$ is $1.91 \AA$. Each of the four equivalent $\mathrm{As}-\mathrm{B}-\mathrm{As}$ angles is $\cos ^{-1}(-1 / 3)^{\circ}$, and each of the six equivalent $\mathrm{O}-\mathrm{B}-\mathrm{O}$ 


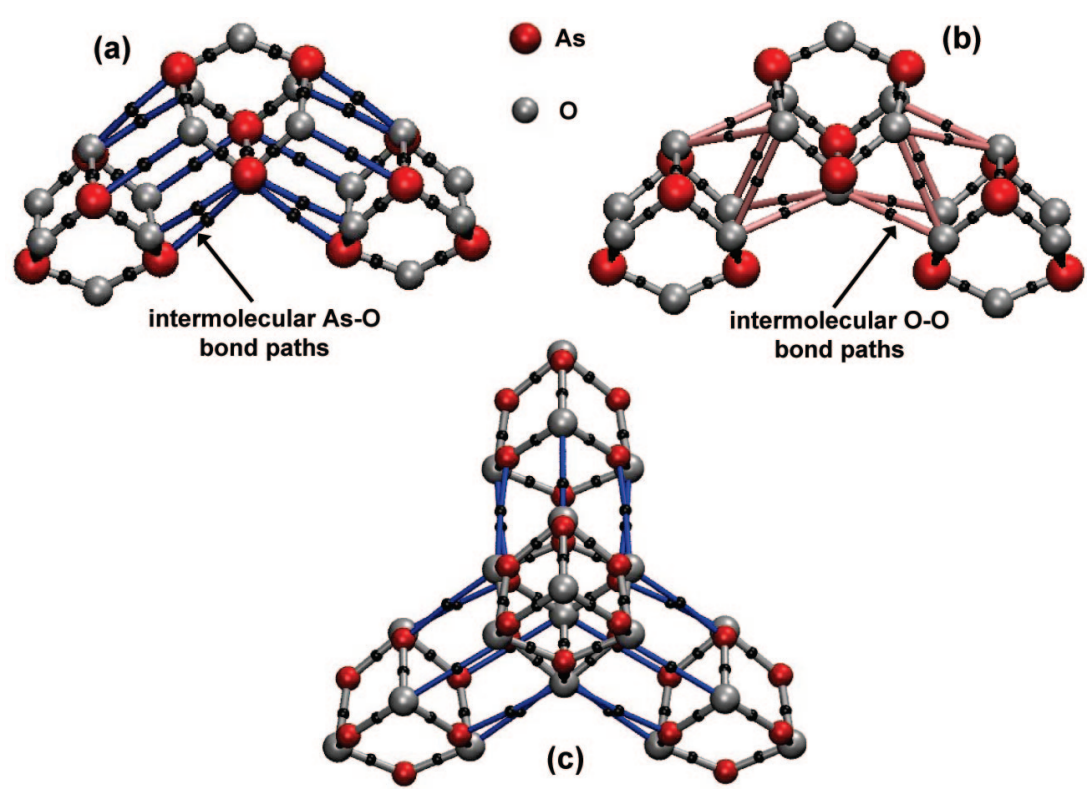

Figure 4. (a) Picture of three equivalent $\mathrm{As}_{4} \mathrm{O}_{6}$ molecules in arsenolite connected by directed $\mathrm{As}-\mathrm{O}$ bond paths. The bond paths direct the molecules in space so that the angle formed at the barycenter of the central molecule and that of the two adjacent molecules is $\cos ^{-1}(-1 / 3)^{\circ}$. The As $-\mathrm{O}$ bond paths are colored blue, and in the following relevant figures, and the black dots along the paths represent the bond critical points. (b) A picture of two equivalent $\mathrm{As}_{4} \mathrm{O}_{6}$ molecules connected by $\mathrm{O}-\mathrm{O}$ directed bond paths colored pink here and in the following relevant figures. (c) Four As $\mathrm{O}_{6}$ molecules disposed about a central molecule by sets of $\mathrm{As}-\mathrm{O}$ directed bond paths that radiate from the tetrahedral faces of the central molecule in a face-to-face mainstay Fisher key-lock fashion.

angles is $90.0^{\circ}$, demonstrating that the As atoms are arranged tetrahedrally and the $\mathrm{O}$ atoms are arranged octahedrally about the barycenter. As such, the angle between each of the four equivalent tetrahedral $\mathrm{As}_{3} \mathrm{O}_{3}$ faces of the molecule is $\cos ^{-1}(-13)^{\circ}$. A geometry optimization of the structure of the molecule at the B3LYP/6-311++(3d) level resulted in $R(\mathrm{As}-\mathrm{O})$ $=1.81 \AA, \mathrm{O}-\mathrm{As}-\mathrm{O}=99.7^{\circ}$, and $\mathrm{As}-\mathrm{O}-\mathrm{As}=126.6^{\circ}$, values that are comparable with the experimental values determined for the arsenolite crystal. An evaluation of the bcp properties of the ED distribution resulted in bond paths only between adjacent As and $\mathrm{O}$ atoms with $\rho\left(\mathbf{r}_{\mathrm{c}}\right)=0.970 \mathrm{e} / \AA^{3}$, the Laplacian $\nabla^{2} \rho\left(\mathbf{r}_{\mathrm{c}}\right)=7.296 \mathrm{e} / \AA^{5}$, the local kinetic energy $G\left(\mathbf{r}_{\mathrm{c}}\right)=0.160$ $\mathrm{au}$, and the local potential energy density $V\left(\mathbf{r}_{\mathrm{c}}\right)=-0.245 \mathrm{au}$ (Table 1). As the total energy density $H\left(\mathbf{r}_{\mathrm{c}}\right)=G\left(\mathbf{r}_{\mathrm{c}}\right)+V\left(\mathbf{r}_{\mathrm{c}}\right)=$ -0.085 au is negative, the interaction qualifies as a shared interaction. ${ }^{19}$ Cremer and Kraka ${ }^{20}$ have promoted the use of $H\left(\mathbf{r}_{\mathrm{c}}\right)$ in an analysis of bond type. When $H\left(\mathbf{r}_{\mathrm{c}}\right)$ is negative, they consider the bond type of a bonded interaction to be shared, whereas when it is positive, it is considered to be a closedshell interaction. Bader and Essen ${ }^{21}$ have asserted that a bonded interaction is shared when $\nabla^{2} \rho\left(\mathbf{r}_{\mathrm{c}}\right)<0$, and Cremer and Kraka ${ }^{20}$ have asserted that a bonded interaction is closed-shell when $H\left(\mathbf{r}_{\mathrm{c}}\right)>0$. On the basis of these constraints, Espinosa et al. ${ }^{22}$ concluded that a bonded interaction is a shared interaction when the ratio $\left|V\left(\mathbf{r}_{\mathrm{c}}\right)\right| / G\left(\mathbf{r}_{\mathrm{c}}\right)>2$, that it is a closed-shell interaction when $\left|V\left(\mathbf{r}_{\mathrm{c}}\right)\right| / G\left(\mathbf{r}_{\mathrm{c}}\right)<1$, and that it is an intermediate interaction when the ratio falls between 1 and 2 . The $\left|V\left(\mathbf{r}_{\mathrm{c}}\right)\right| / G\left(\mathbf{r}_{\mathrm{c}}\right)$ ratio, 1.53, calculated for the molecule indicates that the As-O bonded interaction is a bond of intermediate type rather than a shared interaction.

If we assume, contrary to Feynman's ${ }^{2}$ and Slater's ${ }^{3}$ arguments, that van der Waals forces are indeed nondirectional, then the $\mathrm{As}_{4} \mathrm{O}_{6}$ molecules in arsenolite should adopt a close-packed structure with each molecule surrounded roughly by 12 nearestneighbor molecules. But this is not the case. Each molecule is actually surrounded by four equivalent nearest-neighbor molecules arranged instead at the corners of a tetrahedron, with a separation of $4.795 \AA$ between each barycenter. In fact, the molecules are arranged in exactly the same way as the silicate tetrahedra are arranged in the high temperature, low density, high cristobalite structure of silica. As such, the angle between the barycenter of each of the molecules in arsenolite is $\cos ^{-1}(-13)^{\circ}$, the same as the angle between each of the tetrahedral faces of the molecule. If the van der Waals forces are directional as asserted by Tsirelson et al., ${ }^{6}$ then the tetrahedral array of the $\mathrm{As}_{4} \mathrm{O}_{6}$ molecules in arsenolite should be related to sets of tetrahedrally directed van der Waals forces that emanate from atoms of each of the tetrahedral faces of the molecule. To establish whether such bond paths exist, the bond paths were calculated for arsenolite. The calculation not only resulted in equivalent intramolecular As-O directed bond paths between the nearest-neighbor As and $\mathrm{O}$ atoms of the molecule, but also less stabilizing parallel sets of intermolecular van der Waals directed $\mathrm{O}-\mathrm{O}$ bond paths were found to connect the tetrahedral faces of the adjacent $\mathrm{As}_{4} \mathrm{O}_{6}$ molecules of the structure. Figure 4a displays three adjacent $\mathrm{As}_{4} \mathrm{O}_{6}$ molecules in the structure and the intermolecular van der Waals As-O bonds paths that are associated with the molecules. The bond paths are directed from the As and $\mathrm{O}$ atoms of the central molecule toward the $\mathrm{O}$ and As atoms of two adjoining molecules, respectively, resulting in an angle of $\cos ^{-1}(-1 / 3)^{\circ}$ between the barycenter of the central molecular and those of the two adjoining molecules. Figure $4 \mathrm{~b}$ displays two adjoining $\mathrm{As}_{4} \mathrm{O}_{6}$ molecules as they are connected in the structure by six van der Waals $\mathrm{O}-\mathrm{O}$ directed bond paths. In this case, the paths connect the $\mathrm{O}$ atoms of the two molecules along two parallel $\mathrm{As}_{3} \mathrm{O}_{3}$ tetrahedral faces of the molecule. Collectively, the As-O and $\mathrm{O}-\mathrm{O}$ bond paths in arsenolite are directed from the tetrahedral faces of each $\mathrm{As}_{4} \mathrm{O}_{6}$ molecule, resulting in a periodic tetrahedral structure by virtue of the directed character of the bond paths and the mainstay face-to-face Fischer key-lock arrangement as illustrated by the As-O intramolecular van der Waals paths displayed in Figure 4c. This result indicates that van der Waals forces are indeed directional as argued by Bader et al. ${ }^{5}$ from theoretical considerations and concluded by Tsirelson et al. ${ }^{6}$ in their study of solid molecular chlorine. 


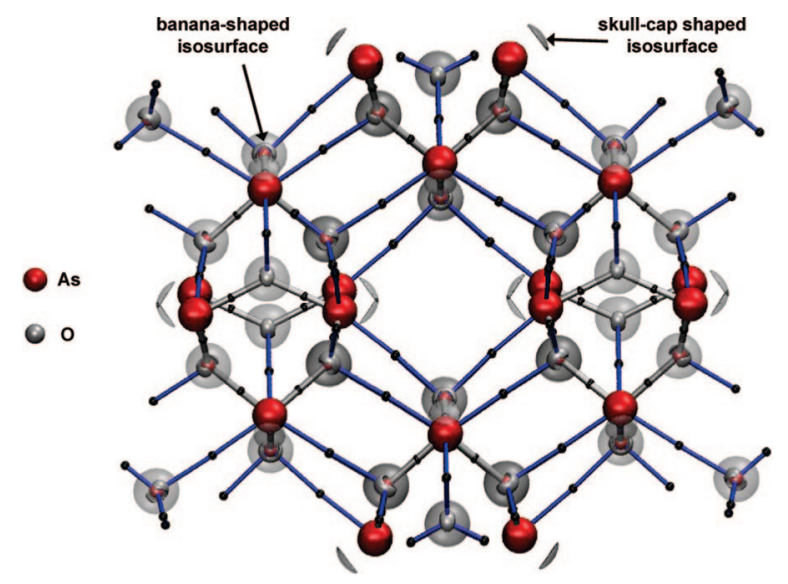

Figure 5. $L(\mathbf{r})$ isosurface mapping of the arsenolite structure viewed down [110]. The blue lines denote the intermolecular As $-\mathrm{O}$ bond paths that the connect red sphere (Lewis acid domain) surrounding each As atom and the banana-shaped lone pair (Lewis base domain) capping each $\mathrm{O}$ atom, qualifying as a Lewis acid-base interaction. The intramolecular As $-\mathrm{O}$ bond paths are colored silver.

The bond critical point property values for the intramolecular As $-\mathrm{O}$ bonded interactions $\left(\rho\left(\mathbf{r}_{\mathrm{c}}\right)=0.99 \mathrm{e} / \AA^{3}, \nabla^{2} \rho\left(\mathbf{r}_{\mathrm{c}}\right)=7.87\right.$ $\mathrm{e} / \AA^{5}, G\left(\mathbf{r}_{\mathrm{c}}\right)=0.159 \mathrm{au}, V\left(\mathbf{r}_{\mathrm{c}}\right)=-0.237 \mathrm{au}, H\left(\mathbf{r}_{\mathrm{c}}\right)=-0.078$ au, $\left.\left|V\left(\mathbf{r}_{\mathrm{c}}\right)\right| / G\left(\mathbf{r}_{\mathrm{c}}\right)=1.49\right)$ for arsenolite are comparable with those calculated for the molecule (Table 1). The intramolecular As-O total bond path length, $1.808 \AA$, is the same as the intramolecular As $-\mathrm{O}$ bond length, demonstrating that the bond paths are essentially straight. The $\rho\left(\mathbf{r}_{\mathrm{c}}\right), \nabla^{2} \rho\left(\mathbf{r}_{\mathrm{c}}\right)$, and $H\left(\mathbf{r}_{\mathrm{c}}\right)$ values calculated for the intermolecular $\mathrm{As}-\mathrm{O}$ and $\mathrm{O}-\mathrm{O}$ interactions are $0.085 \mathrm{e} / \AA^{3}, 0.928 \mathrm{e} / \AA^{5},+0.001$ au and $0.073 \mathrm{e} / \AA^{3}, 0.912$ $\mathrm{e} / \AA^{5},+0.001$ au, respectively. The intermolecular $\mathrm{As}-\mathrm{O}$ separation is substantially shorter, $3.05 \AA$, than the sum of the van der Waals radii for As and $\mathrm{O}, 1.85 \AA+1.52 \AA=3.37 \AA$, respectively, indicating that the closed-shell intermolecular bonded interaction is stronger than a typical As-O van der Waals bonded interaction. The $\mathrm{O}-\mathrm{O}$ separation, $3.022 \AA$, is comparable with the sum of the van der Waals radii, as expected in that it is a substantially weaker interaction. As the $H\left(\mathbf{r}_{\mathrm{c}}\right)$ values for the intermolecular $\mathrm{As}-\mathrm{O}$ and $\mathrm{O}-\mathrm{O}$ interactions are both positive and small in value, they qualify as closed-shell interactions as observed for the $\mathrm{O}-\mathrm{O}$ interactions in minerals..$^{23,24}$ As observed by Tsirelson et al., ${ }^{6}$ closed-shell interactions stabilize a structure by lowering the potential energy by the concentration of the ED in the basins of each of the bonded atoms. They also assert that the small value of $\rho\left(\mathbf{r}_{\mathrm{c}}\right)$ associated with a closed-shell interaction does not necessarily imply a weak interaction. The value of $\rho\left(\mathbf{r}_{\mathrm{c}}\right)$ for the As-O intermolecular interaction is $\sim 15 \%$ larger $\left(0.085 \mathrm{e} / \AA^{3}\right)$ than the value for the $\mathrm{O}-\mathrm{O}$ interaction $\left(0.073 \mathrm{e} / \AA^{3}\right)$, suggesting that the As-O interaction is stronger and plays a more important role in determining the molecular structure of arsenolite.

To establish whether a connection can be made between the intermolecular $\mathrm{As}-\mathrm{O}$ and the $\mathrm{O}-\mathrm{O}$ directed bond paths and the Lewis base-acid and base-base pairs as observed for solid molecular chlorine, composite Laplacian $L(\mathbf{r})$ isosurface contour maps (Figures 5 and 6, respectively) were constructed for the arsenolite crystal structure viewed in a projection down $\sim[110]$. The silver-colored banana-shaped isosurface capping each $\mathrm{O}$ atom on the reflex side of each $\mathrm{As}-\mathrm{O}-\mathrm{As}$ angle was generated at the +12 au level. These isosurfaces define well-developed Lewis base (lone pair) domains where the ED is locally chargeconcentrated. In contrast, the red-colored spherical isosurface surrounding each As atom, generated at the -22 au level,

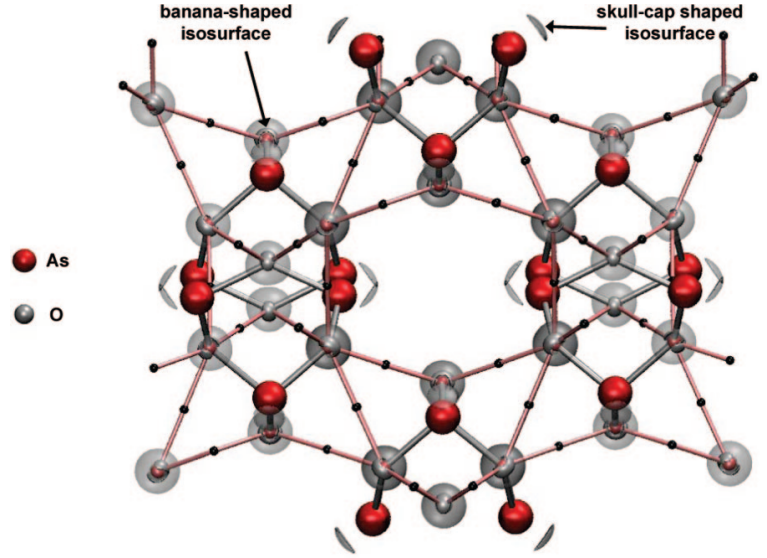

Figure 6. $L(\mathbf{r})$ isosurface mapping of the arsenolite structure viewed down [110]. The pink lines denote the intermolecular $\mathrm{O}-\mathrm{O}$ bond paths. These paths pass through the banana-shaped lone pair domains of the $\mathrm{O}$ atoms and qualify as Lewis base-base interactions.

represents a domain where the ED has been locally chargedepleted, identifying a well-defined spherical Lewis acid domain enclosing each As atom. Further, the silver skullcap-shaped isosurface on the As atom at the apex of each $\mathrm{AsO}_{3}$ pyramidal unit, generated at the +0.01 au level, represents a relatively diffuse Lewis base (lone pair) domain. The bond paths between the intramolecular As and $\mathrm{O}$ atoms are colored silver. Each of the $L(\mathbf{r})$ isosurface contour maps presented in this study were calculated at the same contour level and color-coded as those used to generate the isosurfaces maps for arsenolite. Also, all of the intermolecular As-O, As-As, and $\mathrm{O}-\mathrm{O}$ bond paths are color-coded blue, green, and pink, respectively. The bond critical points are depicted as a black dots along each of the bond paths. For each of the intramolecular shared bonded interactions examined in this study, $H\left(\mathbf{r}_{\mathrm{c}}\right)$ is negative, whereas for the intermolecular van der Waals closed-shell interactions, $H\left(\mathbf{r}_{\mathrm{c}}\right)$ is positive and small in magnitude.

For comparison, a picture of a composite Laplacian isosurface map, generated for the single $\mathrm{As}_{4} \mathrm{O}_{6}$ molecule, is displayed in Figure $3 \mathrm{~b}$. As the optimized geometry of the molecule, bond critical point properties, local energy density properties (Table 1), and the composite Laplacian isosurface features are virtually the same as those of the $\mathrm{As}_{4} \mathrm{O}_{6}$ molecule in the arsenolite crystal, it is apparent that the bonded interactions of the molecule in arsenolite are only slighted perturbed by the force of the crystal field. The question comes to mind: can the tetrahedral periodic array of the $\mathrm{As}_{4} \mathrm{O}_{6}$ molecules adopted in the structure of arsenolite be understood in terms of the mainstay directed bond paths involving Lewis acid-base and the base-base pair domains in much the same way that the layer structure of solid chlorine can be understood in terms of the alignment of such domains and the directed bond paths? As displayed in Figure 5 , each intermolecular As-O bond path passes through the spherical acid domain of the As atom and is directed at the banana-shaped Lewis base domain of an $\mathrm{O}$ atom, qualifying as a Lewis acid-base pair directed bond path. In contrast, each $\mathrm{O}-\mathrm{O}$ bond path in Figure 6 passes through banana-shaped Lewis base domain of one of the $\mathrm{O}$ atoms and is directed at the banana-shaped Lewis base domain of the other $\mathrm{O}$ atom near the end of the $\mathrm{O}-\mathrm{O}$ path. As such, it qualifies as a Lewis base-base pair directed bond path. With these directed bond paths, the structure of arsenolite can be understood, as discussed above, in terms of the bond paths with each adopting a direction that is perpendicular to the tetrahedral faces of each $\mathrm{As}_{4} \mathrm{O}_{6}$ molecule, resulting in a tetrahedral arrangement of $\mathrm{As}_{4} \mathrm{O}_{6}$ 


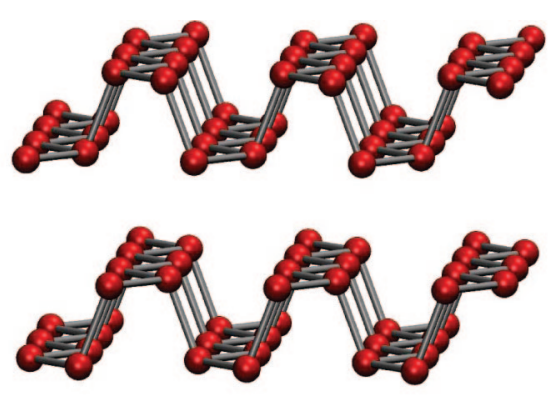

(a)

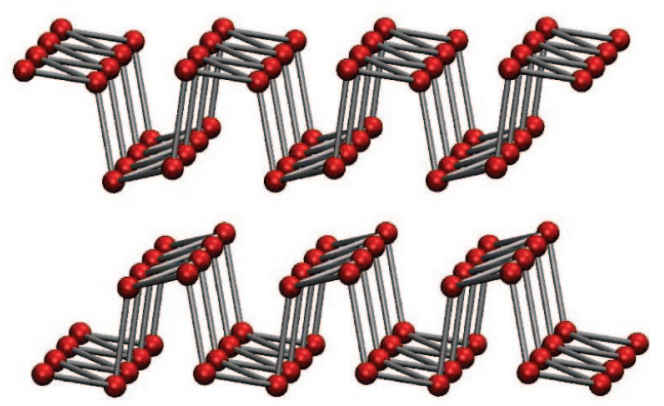

(b)

Figure 7. Two representative layers of the three-coordinated As atoms in the structures of (a) arsenolamprite, $\varepsilon$-As, and (b) claudetite I. By placing three $\mathrm{O}$ atoms about each As in arsenolamprite, the claudetite I structure can be generated, or by removing the $\mathrm{O}$ atoms from the claudetite I structure, the arsenolamprite structure can be derived. It is noteworthy that upon heating, claudetite I disproportionates into arsenolamprite and $\mathrm{As}_{2} \mathrm{O}_{5}$, demonstrating the close connection between the two structures (ref 17).

molecules about each molecule. As the directed bond paths radiate from each of the four tetrahedral faces of the central $\mathrm{As}_{4} \mathrm{O}_{6}$ molecule, the resulting tetrahedral cubic periodic structure can be understood in much the same way as the layered structure of molecular chlorine can be understood in terms of directed bond paths. In a study of the ED for two $\mathrm{Sb}_{2} \mathrm{O}_{3}$ polymorphs, Whitten et al. ${ }^{25}$ reported that molecular $\mathrm{Sb}_{4} \mathrm{O}_{6}$ units for the senarmonite polymorph pack in a mainstay face-to-face key-lock arrangement as displayed for the $\mathrm{As}_{4} \mathrm{O}_{6}$ units in arsenolite. Accordingly, the cubic structure adopted by senarmonite can likewise be explained in terms the Lewis base-acid directed $\mathrm{Sb}-\mathrm{O}$ bond paths and the tetrahedral arrangement of the $\mathrm{Sb}_{4} \mathrm{O}_{6}$ molecular units of the structure.

Claudetite I. Unlike arsenolite, which consists of a periodic array of $\mathrm{As}_{4} \mathrm{O}_{6}$ molecules with a finite number of $\mathrm{As}$ and $\mathrm{O}$ atoms in the ratio two to three, claudetite I consists of a periodic array of highly corrugated molecular sheets with an indeterminate number of As and $\mathrm{O}$ atoms in the ratio of two to three. Each sheet consists of six-membered rings of two nonequivalent $\mathrm{AsO}_{3}$ units, $\mathrm{As}_{1} \mathrm{O}_{3}$ and $\mathrm{As} 2 \mathrm{O}_{3}$, with average bond lengths of 1.792 and $1.787 \AA$, respectively, and average $\mathrm{O}-\mathrm{As}-\mathrm{O}$ angles of $95.16^{\circ}$ and $95.95^{\circ}$, respectively. The average bond length for the two is $\sim 0.02 \AA$ shorter than that observed for arsenolite. There are three nonequivalent $\mathrm{As} 1-\mathrm{O}-\mathrm{As} 2$ angles linking the $\mathrm{AsO}_{3}$ units in the layers: $\mathrm{As} 1-\mathrm{O} 1-\mathrm{As} 2=134.83^{\circ}$, As1-O2-As2 $=125.67^{\circ}$, and As $1-\mathrm{O} 3-\mathrm{As} 2=124.97^{\circ}$ with two of the angles agreeing with the angle observed for arsenolite within $\sim 1^{\circ}$.

The arrangement of the As atoms in claudetite I is comparable with that of As atoms in arsenolamprite (Figure 7). As such, the layers of As atoms in claudetite I can be viewed as a stuffed derivative of layers in the arsenolamprite structure with $\mathrm{O}$ atoms placed in the layers between two As atoms forming an array of $\mathrm{AsO}_{3}$ units. Like claudetite, the As atoms in arsenolamprite form

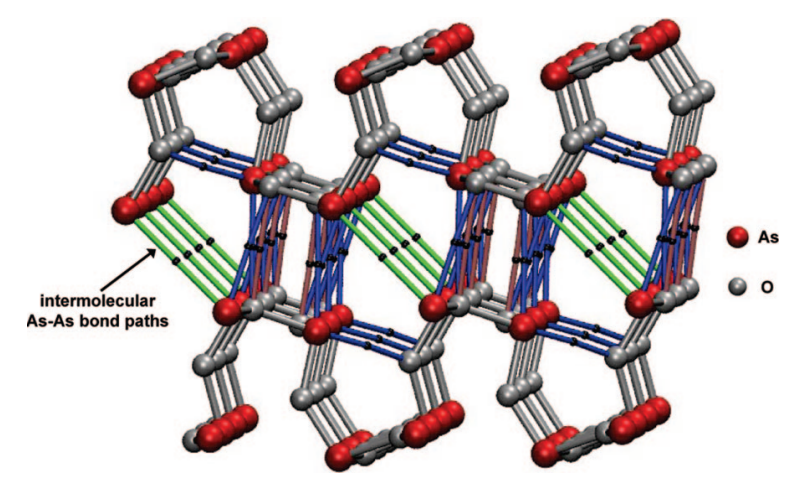

Figure 8. Picture of the claudetite I structure with the As atoms colored red and the $\mathrm{O}$ atoms colored silver. The intramolecular $\mathrm{As}-\mathrm{O}$ bond paths are colored silver, and the intermolecular $\mathrm{As}-\mathrm{O}, \mathrm{O}-\mathrm{O}$, and the As-As directed bond paths are colored blue, pink, and green respectively. The highly corrugated nature of the layers is related to a relatively large number of intermolecular parallel directed bond paths and particularly to the set of $\mathrm{As}-\mathrm{O}$ bond paths that occur near the crest of each corrugated layer.

a layer structure connected by intramolecular As-As shared bonded interactions where each As atom is connected by bond paths to three As atoms with two at $2.31 \AA$ and one at $2.29 \AA$ with an As-As-As angle of $103.8^{\circ}$ between the short bond paths and an angle of $102.4^{\circ}$ between the short and long bond paths. With the stuffing of the $\mathrm{O}$ atoms in the arsenolamprite structure, the longer intramolecular As-As separation increases to $3.19 \AA$ and the short one increases to $3.28 \AA$ while the angles between the long and short As separations widen to $104.9^{\circ}$ and the angle between the shorter separations narrows to $91.1^{\circ}$. The bonded radius of the $\mathrm{O}$ atom involving the intramolecular $\mathrm{As}-\mathrm{O}$ bond length, $\sim 0.95 \AA$, is slightly greater than the bonded radius of the $\mathrm{O}$ atom $\left(r_{\mathrm{b}}(\mathrm{O})=0.87 \AA\right)$ in claudetite I yet substantially smaller than the three-coordinate ionic radius $(1.35 \AA)$ of the $\mathrm{O}$ atom. ${ }^{26}$ Also, the intramolecular As-As separations (3.530, $3.878,4.013 \AA$ ) between the layers in arsenolamprite are slightly longer, on average (3.808 $⿱$ A), than the intermolecular As-As bond in claudetite I (3.728 $)$.

Bond paths exist in claudetite I along each of the nonequivalent intramolecular $\mathrm{As}-\mathrm{O}$ bonded interactions comprising the layers. On the basis of the local kinetic and potential energy density for the interactions, each qualifies, as observed for the As-O intramolecular bonded interactions in arsenolite, as a shared interaction of intermediate character (Table 1). In addition, intermolecular van der Waals directed bond paths exist between and bind the layers into a coherent layered structure. There are three types of intermolecular paths: an As-As bond path of length $3.278 \AA$, an $\mathrm{O}-\mathrm{O}$ bond path of length $3.361 \AA$, and three As $-\mathrm{O}$ bond paths of lengths 3.038, 3.356, and 3.428 $\AA$. These paths are delineated in Figure 8. The highly corrugated nature of the layer is directly related to the set of short (3.038 $\AA$ A) directed parallel interlayer As-O bonded interactions within the layer. In particular, the set only involves the As and $\mathrm{O}$ atoms within the layer unlike the shorter intramolecular bonded interactions. Further, as the bonded interaction has a greater strength than the other intermolecular interaction, its presence enhances the corrugation of the layer (Figure 8). The bond critical point properties $\left(\rho\left(\mathbf{r}_{\mathrm{c}}\right)=0.051 \mathrm{e} / \AA^{3}, \nabla^{2} \rho\left(\mathbf{r}_{\mathrm{c}}\right)=0.415\right.$ $\mathrm{e} / \AA^{5}$ ) for the intermolecular As-As interaction are comparable with the corresponding one in arsenolamprite $\left(\rho\left(\mathbf{r}_{\mathrm{c}}\right)=0.046\right.$ $\left.\mathrm{e} / \AA^{3}, \nabla^{2} \rho\left(\mathbf{r}_{\mathrm{c}}\right)=0.428 \mathrm{e} / \AA^{5}\right)($ Table 1$)$. This agreement indicates that the bonded interactions between the As atoms in claudetite I are virtually the same as those that bind the layers of As atoms in arsenolamprite. On the basis of the similarity of the local 


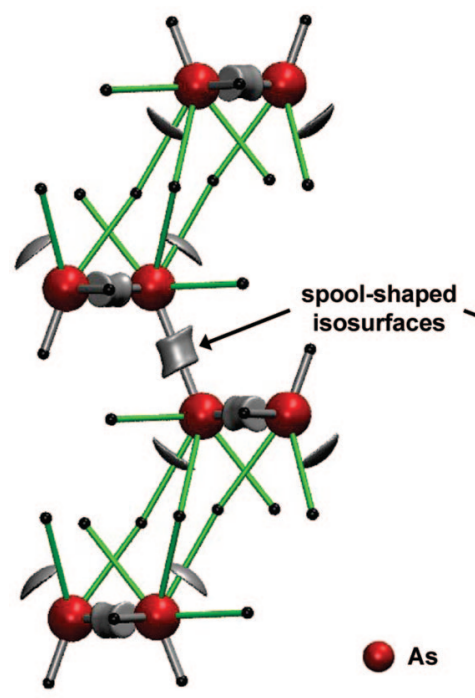

(a)

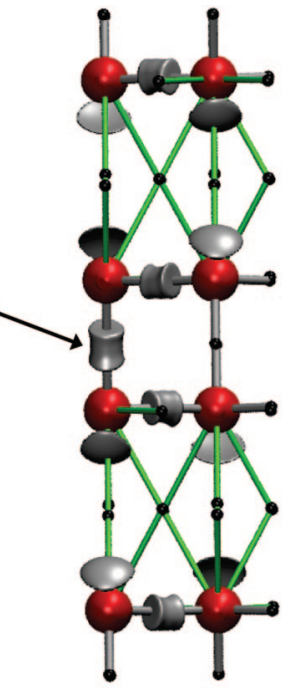

(b)

Figure 9. Pictures of the $L(\mathbf{r})$ isosuface maps of the arsenolamprite structure viewed (a) down [010] and (b) down [100]. The arsenic atoms are colored red, the intramolecular bond paths are colored silver, and the intermolecular bond paths are colored green. Two of the intermolecular As-As bond paths pass through the skullcap-shaped lone pairs domain of one of the As atoms. The intramolecular As-As bond paths are centered with a spool-shaped bond pair domain. The presence of these domains between the intramolecular As-As pairs within the layer and their absence between the intermolecular pairs demonstrates that arsenolamprite is a molecular crystal akin to claudetite I and II.

kinetic and potential energy densities (Table 1), the intermolecular bonded interactions for both claudetite I and arsenolamprite qualify as closed-shell ionic interactions. The $\rho\left(\mathbf{r}_{\mathrm{c}}\right)$ values for the $\mathrm{As}-\mathrm{O}$ intermolecular interactions $\left(0.066 \mathrm{e} / \AA^{3}\right)$ are larger, on average, than the $\mathrm{As}-\mathrm{As}\left(0.056 \mathrm{e} / \AA^{3}\right)$ and $\mathrm{O}-\mathrm{O}$ bonded interactions $\left(0.045 \mathrm{e} / \AA^{3}\right)$, again suggesting that the $\mathrm{As}-\mathrm{O}$ intermolecular interactions play a dominate role as mainstays in determining the molecular structure.

$L(\mathbf{r})$ isosurface maps together with the intermolecular As-As bond paths were generated for arsenolamprite in views down [010] (Figure 9a) and [001] (Figure 9b) to clarify the connections between the paths and the domains ascribed to the bonded and nonbonded electron pairs and to determine the correspondence between the topological properties of the intermolecular As-As bond interactions in arsenolamprite and claudetite I (Figure 10). As observed for the As atoms in the isolated $\mathrm{As}_{4} \mathrm{O}_{6}$ molecule and for arsenolite, each As atom is enclosed by a region of charge depletion and capped by a skullcap-shaped lone pair domain (Figures $3 \mathrm{~b}$ and 5, respectively). However, unlike the intermolecular As-As bond paths in arsenolamprite, the intramolecular As-As paths are centered by a spool-shaped feature ascribed to a bond pair domain. However, the intermolecular As-As bond paths lack the domain and are similar to those in claudetite I. Of the three intermolecular paths, two pass through the skullcap Lewis base domain, whereas the other one bypasses the domain. As observed above, all three qualify as closed-shell interactions with the two As-As bond paths passing through the skullcap-shaped domain and qualify as a Lewis acid-base bonded interaction. However, the third intermolecular As-As interaction qualifies as a Lewis acid-acid bonded interaction.

Isosurface $L(\mathbf{r})$ maps and the bond paths for claudetite I are displayed for the $\mathrm{O}-\mathrm{O}$, As-O, and the As-As intermolecular van der Waals interactions in a projection of the structure viewed down [001]. The directed parallel $\mathrm{O}-\mathrm{O}$ bond paths involve the

lone-pair features on the $\mathrm{O}$ atoms and qualify as Lewis base-base pair interactions (Figure 10a); the directed parallel As-O bond paths involve the spherical acid domain on the As atoms and the Lewis base on the $\mathrm{O}$ atoms and qualify as a Lewis base-acid pair (Figure 10b). The As-As bond path plays the same role as the As-As path in arsenolamprite and qualifies as a Lewis acid-acid pair bonded interaction (Figure 10c).

Claudetite II. Unlike claudetite I, the claudetite II structure is more regular with one nonequivalent $\mathrm{AsO}_{3}$ pyramid with an average bond length of $1.787 \AA$, an average $\mathrm{O}-\mathrm{As}-\mathrm{O}$ angle of $98.95^{\circ}$, and an average As- $\mathrm{O}-\mathrm{As}$ angle of $123.60^{\circ}$. Further, the individual As-O bond lengths and the $\mathrm{O}-\mathrm{As}-\mathrm{O}$ and As-O-As angles show a small departure from their average values. The number and types of nonequivalent van der Waals bond paths in claudetite II (one As-O (2.958 $\AA$ ) and one As-As bond path, $3.701 \AA$ ) are fewer in number than observed for claudetite I, providing a basis for understanding why its layers are less corrugated. Unlike claudetite I, claudetite II lacks an intermolecular As- $\mathrm{O}$ directed bond path between the atoms in a single layer that imparts the greater corrugation of the layer in claudetite I.

In an examination of the relative stability of the corrugated layers in claudetite I, a single layer of the structure was geometry-optimized. As the geometry-optimized layer is similar in structure to that in claudetite II, it was concluded that the corrugated layer in claudetite I is destabilized relative the one in claudetite II and that the intermolecular As-O interactions within the layer in claudetite I play a dominate role imparting the corrugation of the layer. The parallel sets of the directed As $-\mathrm{O}$ and As-As bond paths in claudetite II are delineated in Figure 11, and $L(\mathbf{r})$ isosurface maps of the two interactions are displayed in Figure 12. Given the spherical Lewis acid domain surrounding each As atom and the banana-shaped lone pair on each $\mathrm{O}$, the As-O interactions involve a Lewis acid-base pair interaction (Figure 12a). As observed for claudetite I, the As-As interaction seems to play the same role that it plays in arsenolamprite (Figure 12b) and qualifies as a Lewis acid-acid bonded interaction. As before, the value of $\rho\left(\mathbf{r}_{\mathrm{c}}\right)$ for the As-O interaction $\left(0.101 \mathrm{e} / \AA^{3}\right)$ is larger than that for the As-As interaction $\left(0.052 \mathrm{e} / \AA^{3}\right)$, evidence that suggests the As-O interaction is stronger than the As-As interaction.

$\mathrm{AsO}_{2}$ and $\mathrm{As}_{2} \mathrm{O}_{5}$. For purposes of comparison, the bond critical point, the local energy properties, and $L(\mathbf{r})$ isosurface maps were calculated for two additional arsenates, $\mathrm{AsO}_{2}{ }^{27}$ (Table 1) and $\mathrm{As}_{2} \mathrm{O}_{5} .{ }^{28}$ Like the $\mathrm{As}_{2} \mathrm{O}_{3}$ polymorphs, $\mathrm{AsO}_{2}$ is a molecular crystal and consists of layers of six-membered rings, paralleling (100). But, unlike the $\mathrm{As}_{2} \mathrm{O}_{3}$ polymorphs, it contains $\mathrm{AsO}_{4}$ tetrahedral units together with $\mathrm{AsO}_{3}$ pyramidal units in perfect alternation with all of the $\mathrm{O}$ atoms of the pyramids shared in common between three tetrahedra and with three of the tetrahedra shared in common with pyramidal units, leaving one of the $\mathrm{O}$ atoms on the tetrahedral unit as a terminal $\mathrm{O}$. Two of the three ${ }^{\text {III }} \mathrm{As}-\mathrm{O}$ bond lengths $(1.794 \AA$ ) are comparable with those of the claudetites, whereas the third is slightly longer $(1.818 \AA)$. The ${ }^{\mathrm{IV}} \mathrm{As}-\mathrm{O}$ bonded interactions bonded to the bridging $\mathrm{O}$ atoms of the $\mathrm{AsO}_{3}$ pyramids are $1.713 \AA(2 \times)$ and $1.724 \AA$ in length, whereas the bond interaction involving the unshared terminal $\mathrm{O}$ is substantially shorter, $1.611 \AA$. As expected, the three $\mathrm{O}-{ }^{\mathrm{IV}} \mathrm{As}-\mathrm{O}$ angles involving the terminal $\mathrm{O}$ atom are substantially wider $\left(112.45^{\circ}(2 \times), 119.40^{\circ}\right)$ than those involving the bridging $\mathrm{O}$ atoms. However, the three ${ }^{\mathrm{III}} \mathrm{As}-\mathrm{O}-{ }^{\mathrm{IV}} \mathrm{As}$ angles between the $\mathrm{AsO}_{3}$ and $\mathrm{AsO}_{4}$ units are virtually the same, each agreeing within $0.5^{\circ}$ of the average value $\left(125.1^{\circ}\right)$. As observed for the $\mathrm{As}_{2} \mathrm{O}_{3}$ polymorphs, the 


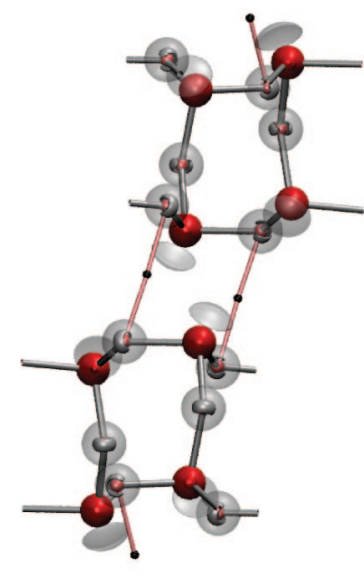

(a)

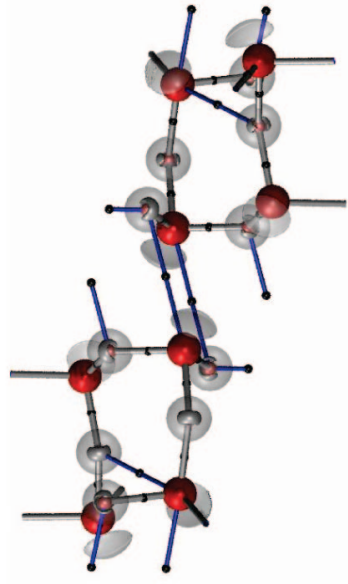

(b)

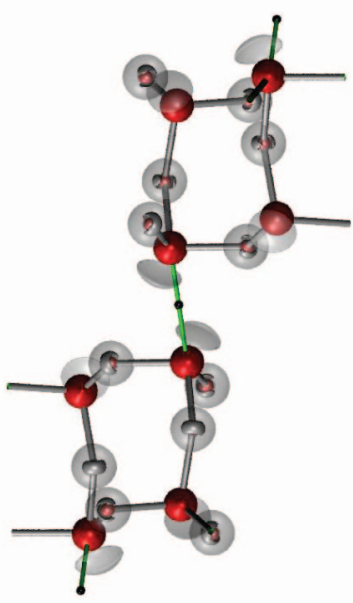

(c)

Figure 10. Pictures of $L(\mathbf{r})$ isosurface maps for claudetite I viewed down [001], displaying its directed (a) $\mathrm{O}-\mathrm{O}$ bond paths, (b) As $-\mathrm{O}$ bond paths, and (c) As-As bond paths. The $\mathrm{O}-\mathrm{O}$ paths connect the banana-shaped lone pairs on the $\mathrm{O}$ atoms, and the As-O paths connect the acid sites on the As atoms. The lone pairs on the $\mathrm{O}$ atoms and the As-As pairs are comparable with the intermolecular As-As paths in arsenolamprite.

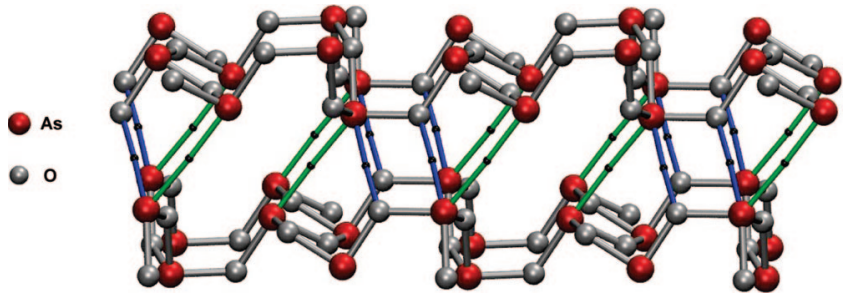

Figure 11. Picture of the claudetite II structure displaying its intramolecular and intermolecular bond paths. The arsenic atoms are colored red, and the $\mathrm{O}$ atoms and the intramolecular bond paths are colored silver. The intermolecular As-As bond paths are colored green, and the As- $\mathrm{O}$ bond paths are colored blue. The layers in claudetite II are much less corrugated than those in claudetite I, a feature that is ascribed to the absence of a van der Waals $\mathrm{As}-\mathrm{O}$ bonded interaction within the sheet.

average value of $\rho\left(\mathbf{r}_{\mathrm{c}}\right)$ for the intermolecular As-O interactions is larger $\left(0.074 \mathrm{e} / \AA^{3}\right)$ than that for the $\mathrm{O}-\mathrm{O}$ interactions $(0.053$ $\left.\mathrm{e} / \AA^{3}\right)$.

A picture of the As-O bond paths and the composite $L(\mathbf{r})$ isosurface map generated for the structure in a view down [010] is given in Figure 13. Each of the bridging $\mathrm{O}$ atoms in the structure is capped by a banana-shaped lone pair domain as observed for the other $\mathrm{As}_{2} \mathrm{O}_{3}$ polymorphs on the reflex side of the ${ }^{\mathrm{III}} \mathrm{As}-\mathrm{O}-{ }^{\mathrm{IV}} \mathrm{As}$ angle. The lone pair on the terminal $\mathrm{O}$ consists of a well-developed ring torus shaped domain that surrounds the atom. Intermolecular As- $\mathrm{O}$ bond paths radiate from each As atom to both the banana-shaped lone pair domains on the bridging $\mathrm{O}$ atoms and the ring torus shaped lone pair on the bridging atom denoted $\mathrm{O} 3$. Five bond paths are directed to the ring torus shaped domains on the terminal $\mathrm{O}$ atoms, two at $3.130 \AA$, two at $3.181 \AA$, and one at $2.942 \AA$, whereas one bond path is directed at the $\mathrm{O} 1$ bridging $\mathrm{O}$ at a distance of $3.427 \AA$. $\mathrm{O}-\mathrm{O}$ bond paths exist but are not shown. One connects two equivalent $\mathrm{O} 1$ atoms at a separation of $3.046 \AA$, and the other connects $\mathrm{O} 2$ and $\mathrm{O} 3$ at a separation of $3.141 \AA$. In addition, a geometry optimization and a calculation of the $L(\mathbf{r})$ and ELF isosurface maps for the $\mathrm{As}_{4} \mathrm{O}_{10}$ molecule also displayed ring torus shaped domains on the terminal $\mathrm{O}$ atoms. Clearly, the intermolecular As-O bonded interaction qualifies as Lewis acid-base pair interactions. Although not shown, the $\mathrm{O}-\mathrm{O}$ interactions qualify as Lewis base-base pair interactions. All of the intermolecular As- $\mathrm{O}$ bonded interactions have positive
$H\left(\mathbf{r}_{\mathrm{c}}\right)$ values and qualify as closed-shell interactions (Table 1). As evinced by Figure 13, the layers in $\mathrm{AsO}_{2}$ are interlocked tightly by the intermolecular $\mathrm{As}-\mathrm{O}$ bond paths that radiate from the terminal $\mathrm{O}$ atoms of the tetrahedral $\mathrm{AsO}_{4}$ units to the As atoms in the adjacent layers.

In contrast, $\mathrm{As}_{2} \mathrm{O}_{5}$ is a nonmolecular structure consisting of a framework of corner-sharing $\mathrm{AsO}_{4}$ tetrahedral and $\mathrm{AsO}_{6}$ octahedral units with six-membered rings of alternating tetrahedra and octahedra and three-membered rings of two octahedra and one tetrahedron. The average ${ }^{\mathrm{IV}} \mathrm{As}-\mathrm{O}$ and ${ }^{\mathrm{VI}} \mathrm{As}-\mathrm{O}$ bond lengths are observed to be 1.675 and $1.818 \AA$, the four nonequivalent ${ }^{\mathrm{VI}} \mathrm{As}-\mathrm{O}-{ }^{\mathrm{VI}} \mathrm{As}$ angles have an average value of $128.6^{\circ}$, and one nonequivalent ${ }^{\mathrm{VI}} \mathrm{As}-\mathrm{O}-{ }^{\mathrm{VI}} \mathrm{As}$ angle is wider, $136.1^{\circ}$. The bcp property data in Table 1 shows that the $\rho(\mathbf{r})$ and $\nabla^{2} \rho(\mathbf{r})$ for the shorter ${ }^{\mathrm{IV}} \mathrm{As}-\mathrm{O}$ bonded interactions are larger than those calculated for the ${ }^{\mathrm{VI}} \mathrm{As}-\mathrm{O}$ interactions with both interaction qualifying as shared interactions. An $L(\mathbf{r})$ composite isosurface map of a representative moiety of the structure shows that each $\mathrm{O}$ atom is capped by a banana-shaped isosurface on the reflex side of the As-O-As angles as observed for all of the other arsenates (Figure 14).

\section{Bond Critical Point Properties}

The bcp properties and the local energy density properties for the $\mathrm{M}-\mathrm{O}$ bonded interactions involving first- and secondrow nontransition and third-row $(\mathrm{Mn}, \mathrm{Co}, \mathrm{Fe})$ transition $\mathrm{M}$ atoms bonded to $\mathrm{O}$ in oxides and silicates are highly correlated with bond length. ${ }^{29}$ For purposes of comparison, the properties were calculated for the intramolecular and intermolecular As-O bonded interactions for the three $\mathrm{As}_{2} \mathrm{O}_{3}$ polymorphs, for the molecular crystal $\mathrm{AsO}_{2},{ }^{27}$ for the intramolecular bonded interactions for $\mathrm{As}_{2} \mathrm{O}_{5},{ }^{28}$ and for a variety of arsenate molecules (Table 1). The $\left|V\left(\mathbf{r}_{\mathrm{c}}\right)\right| / G\left(\mathbf{r}_{\mathrm{c}}\right)$ ratios for intramolecular $\mathrm{As}-\mathrm{O}$ bonded interactions in these materials range between 1.47 and 1.57, whereas the intermolecular interactions range between 0.74 and 0.94. On the basis of these ratios, the intramolecular interactions classify as intermediate interactions as observed above for the $\mathrm{As}_{4} \mathrm{O}_{6}$ molecule and intermolecular ones classify as closed-shell interactions. As displayed in Figure 15, $\rho\left(\mathbf{r}_{\mathrm{c}}\right), \nabla^{2} \rho\left(\mathbf{r}_{\mathrm{c}}\right)$, and $G\left(\mathbf{r}_{\mathrm{c}}\right) /$ $\rho\left(\mathbf{r}_{\mathrm{c}}\right)$ both increase in value as $R(\mathrm{As}-\mathrm{O})$ decreases for both the intermolecular and the intramolecular bonded interactions, a result that suggests that a continuum of bonded interactions 


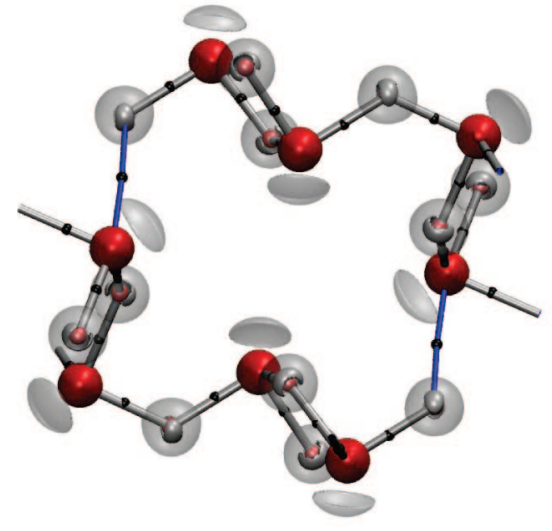

(a)

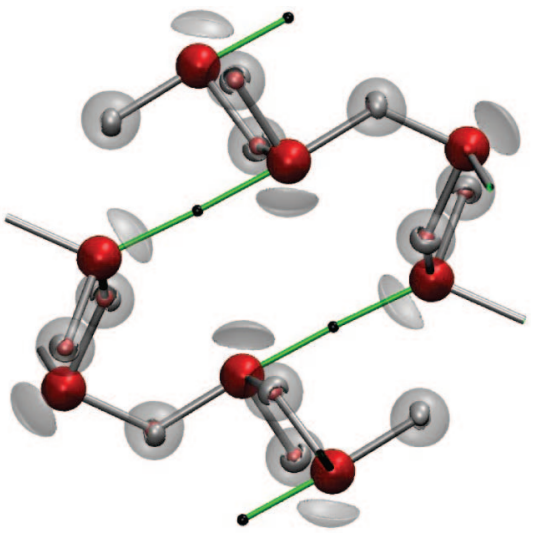

(b)

Figure 12. Pictures of $L(\mathbf{r})$ isosurface maps for claudetite II viewed down $\sim[010]$. Panel a displays the intermolecular As $-\mathrm{O}$ bond paths (colored blue) that pass through the spherical acid domain on the As atoms and the banana-shaped base domain on the $\mathrm{O}$ atoms that qualify as a Lewis base-acid pair interactions, and panel b displays the intermolecular As-As bond paths (colored green) like those observed for arsenolamprite that do not pass through the skullcap domain.

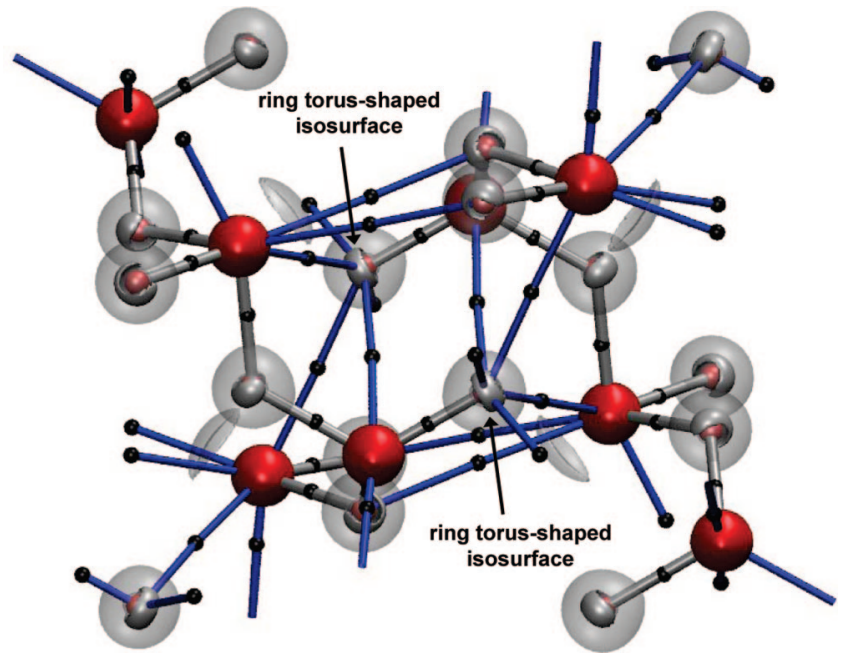

Figure 13. Picture of $L(\mathbf{r})$ isosurface maps for $\mathrm{AsO}_{2}$, a molecular crystal consisting of layers of corner-sharing $\mathrm{AsO}_{3}$ and $\mathrm{AsO}_{4}$ units. All of three corners of the $\mathrm{AsO}_{3}$ pyramids share edges with $\mathrm{AsO}_{4}$ tetrahedra, and three of the four corners of the $\mathrm{AsO}_{4}$ tetrahedra shared edges with $\mathrm{AsO}_{3}$ pyramid leaving one terminal $\mathrm{O}$ atom. The terminal $\mathrm{O}$ atom is surrounded by ring torus shaped isosurfaces, and the bridging $\mathrm{O}$ atoms are capped by banana-shaped isosurfaces located on the reflex side of the As-O-As angles. Five intermolecular $\mathrm{As}-\mathrm{O}$ bond paths (colored blue) connect the spherical Lewis acid domain of the As atoms and the ring torus shaped Lewis base domain on the terminal $\mathrm{O}$ atom. Also, an intermolecular As-O bond path connects the Lewis acid domain on the As atom and the banana-shaped Lewis base on a bridging $\mathrm{O}$ atom. Both types of bond paths qualify as a Lewis base-acid pair directed bond paths.

exists between the two interactions. $H\left(\mathbf{r}_{\mathrm{c}}\right)$ also decreases and becomes more negative in value as $R(\mathrm{As}-\mathrm{O})$ decreases for the intramolecular bonded interactions decrease, but in the case of the intermolecular interactions, $H\left(\mathbf{r}_{\mathrm{c}}\right)$ is largely independent of $R($ As $-\mathrm{O})$. The $\left|V\left(\mathbf{r}_{\mathrm{c}}\right)\right| / G\left(\mathbf{r}_{\mathrm{c}}\right)$ ratios for both the intramolecular and intermolecular interactions are also largely independent of bond lengths. On the basis of the $H\left(\mathbf{r}_{\mathrm{c}}\right)$ values, all of the intermolecular $\mathrm{As}-\mathrm{O}$ bonded interactions with bond lengths greater than $2.8 \AA$ classify as closed-shell interactions and all of the intramolecular interactions with bond lengths less than $2.1 \AA$ A classify as shared interactions. As observed by Bone and Bader, ${ }^{30}$ the sign of $H\left(\mathbf{r}_{\mathrm{c}}\right)$ is determined by the energy density itself, and therefore, it is negative for all interactions that result

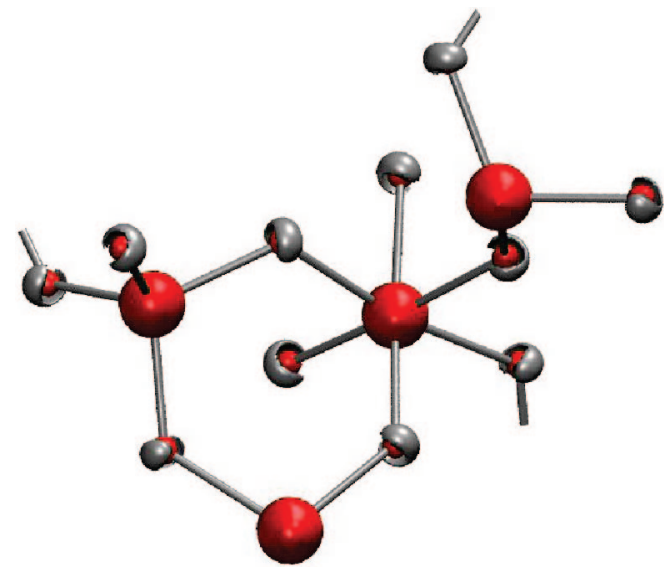

Figure 14. $L(\mathbf{r})$ isosurface map for the framework crystal $\mathrm{As}_{2} \mathrm{O}_{5}$. Unlike the other arsenates, all of the bond paths are intramolecular As $-\mathrm{O}$ interactions.

from an accumulation of ED at $\mathbf{r}_{\mathrm{c}}$. As such, the greater the accumulation, the more negative the value of $H\left(\mathbf{r}_{\mathrm{c}}\right)$ and the more shared the bonded interaction. But as displayed in Figure 15a, $\rho\left(\mathbf{r}_{\mathrm{c}}\right)$ actually increases with decreasing bond length for the intermolecular interactions, yet the value of $H\left(\mathbf{r}_{\mathrm{c}}\right)$ remains largely unchanged. A similar result has been reported for closedshell $\mathrm{Na}-\mathrm{O}$ and $\mathrm{Mg}-\mathrm{O}$ bonded interactions. Bader and Essen ${ }^{21}$ have asserted that a bonded interaction is shared when $\nabla^{2} \rho\left(\mathbf{r}_{\mathrm{c}}\right)$ $<0$ and either an intermediate and closed-shell interaction when $\nabla^{2} \rho\left(\mathbf{r}_{\mathrm{c}}\right)>0$. But in the case of the $\mathrm{M}-\mathrm{O}$ bonded interactions in oxides and silicates, ${ }^{29} \nabla^{2} \rho\left(\mathbf{r}_{\mathrm{c}}\right)$ is positive and becomes progressively larger as $\rho\left(\mathbf{r}_{\mathbf{c}}\right)$ increases and as $H\left(\mathbf{r}_{\mathrm{c}}\right)$ becomes more negative in value. The same trends for the As-O bonded interactions are plotted in Figure 16a where it shows that $\nabla^{2} \rho\left(\mathbf{r}_{\mathrm{c}}\right)$ increases in value with increasing $\rho\left(\mathbf{r}_{\mathrm{c}}\right)$. With the exception of the As-O closed-shell intermolecular interaction, $H\left(\mathbf{r}_{\mathrm{c}}\right)$ is negative and decreases in value as $\nabla^{2} \rho\left(\mathbf{r}_{\mathrm{c}}\right)$ increases (Figure $16 \mathrm{~b})$. The fact that $\nabla^{2} \rho\left(\mathbf{r}_{\mathrm{c}}\right)>0$ and that it increases in magnitude with decreasing bond length indicates that the As $-\mathrm{O}$ bond is a polar covalent bond as observed for double bonds between $\mathrm{C}$ and $\mathrm{O}$ or $\mathrm{S}^{21}$

As observed for the $\mathrm{M}-\mathrm{O}$ bonded interactions for oxides and silicates, and organic metallic oxides, $G\left(\mathbf{r}_{\mathrm{c}}\right) / \rho\left(\mathbf{r}_{\mathrm{c}}\right)$ increases with decreasing bond length. Likewise, for the As-O bonded interactions, $G\left(\mathbf{r}_{\mathrm{c}}\right) / \rho\left(\mathbf{r}_{\mathrm{c}}\right)$ also decreases with decreasing bond 

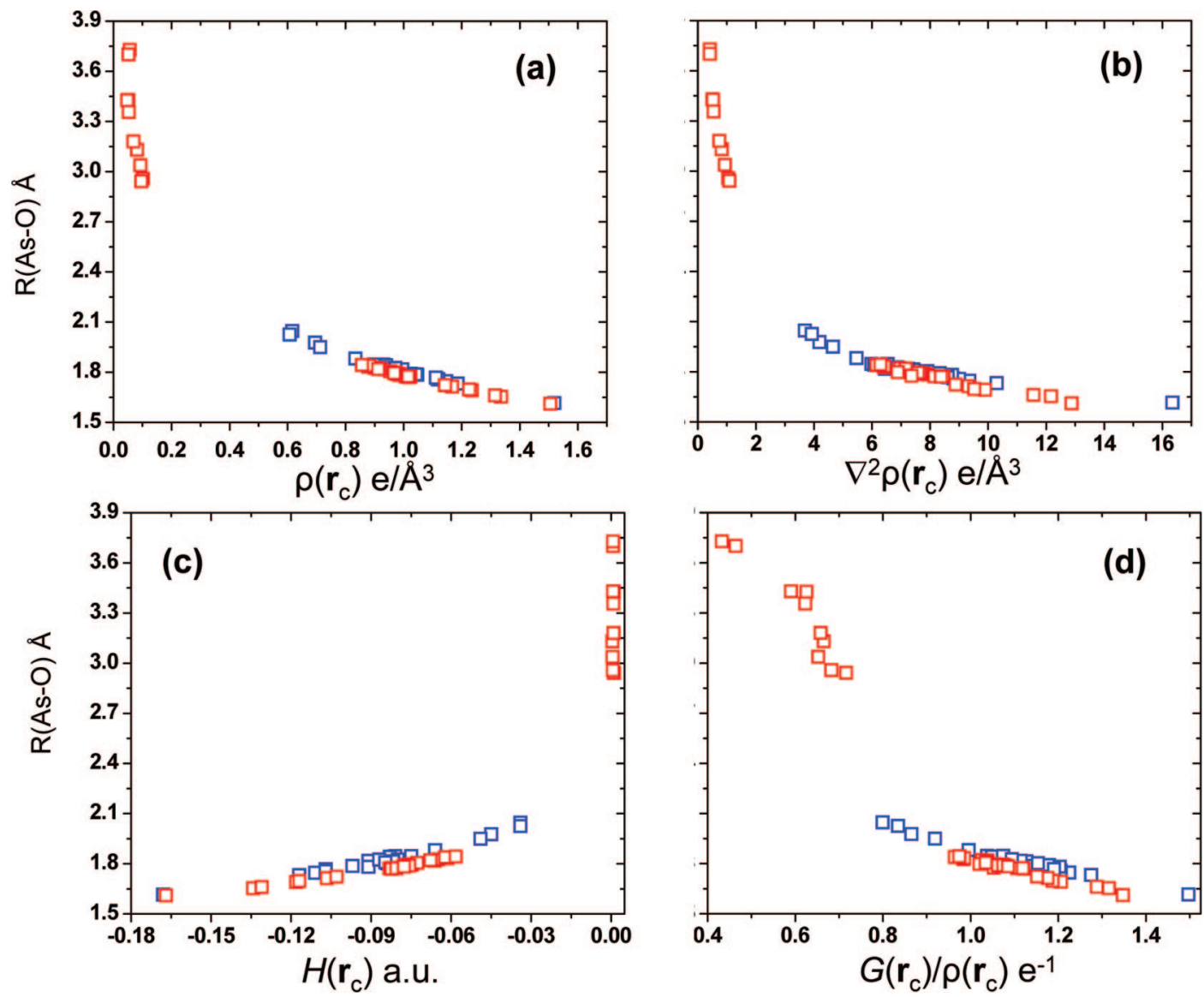

Figure 15. Scatter diagrams of the $\mathrm{As}-\mathrm{O}$ bond length, $R(\mathrm{As}-\mathrm{O})$, for arsenate molecules (blue squares) and crystals (red squares) plotted with respect to (a) the values of $\rho\left(\mathbf{r}_{\mathrm{c}}\right)$ in units of e/ $\AA^{3}$ at the bond critical point $\mathbf{r}_{\mathrm{c}}$, (b) the value of the Laplacian of $\rho\left(\mathbf{r}_{\mathrm{c}}\right), \nabla^{2} \rho\left(\mathbf{r}_{\mathrm{c}}\right)$, in units of e/ $\AA^{5}$, (c) the local energy density, $H\left(\mathbf{r}_{\mathrm{c}}\right)=G\left(\mathbf{r}_{\mathrm{c}}\right)+V\left(\mathbf{r}_{\mathrm{c}}\right)$, in atomic units, au, where $G\left(\mathbf{r}_{\mathrm{c}}\right)$ is the positive definite local kinetic energy density and $V\left(\mathbf{r}_{\mathrm{c}}\right)$ is the negative definite local potential energy density, and (d) the value of $G\left(\mathbf{r}_{\mathrm{c}}\right) / \rho\left(\mathbf{r}_{\mathrm{c}}\right)$ in units of au $\mathrm{e}^{-3}$. Data are taken from Table 1 .
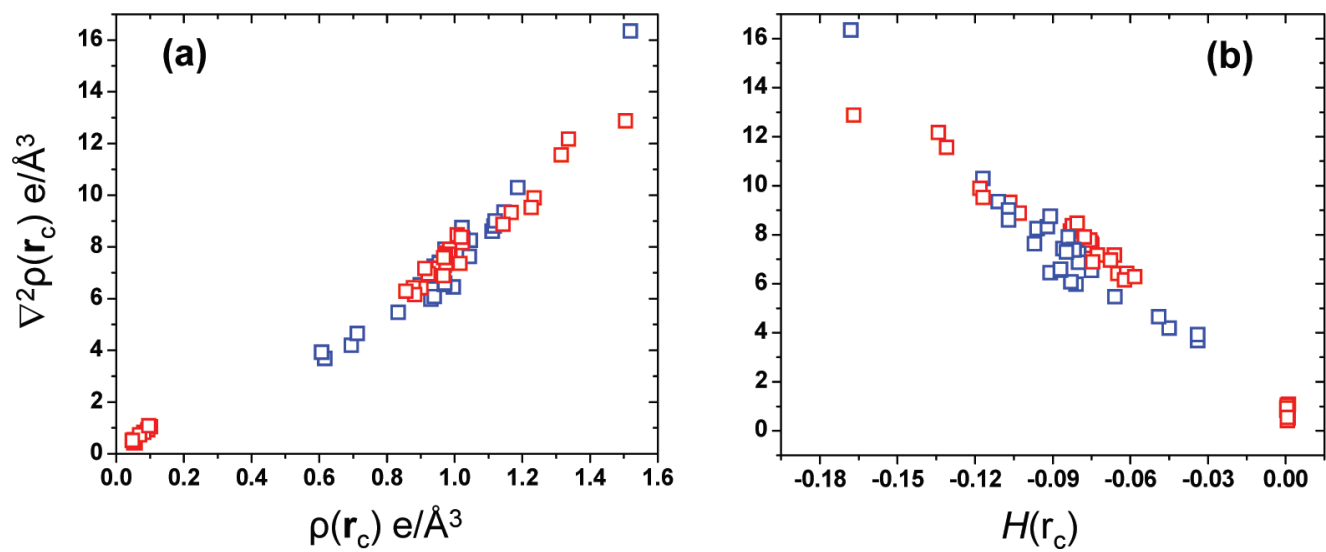

Figure 16. Scatter diagrams of $\nabla^{2} \rho\left(\mathbf{r}_{\mathrm{c}}\right)$ plotted with respect to (a) $\rho\left(\mathbf{r}_{\mathrm{c}}\right)$ and (b) $H\left(\mathbf{r}_{\mathrm{c}}\right.$ ) for arsenate molecules (blue squares) and crystals (red squares). Data taken are from Table 1.

length with the closed-shell interactions exhibiting $G\left(\mathbf{r}_{\mathrm{c}}\right) / \rho\left(\mathbf{r}_{\mathrm{c}}\right)$ values less than 0.8 and the shared interactions exhibiting values greater than 0.8 and as large as 1.5 . These results run contrary to the assertion that $G\left(\mathbf{r}_{\mathrm{c}}\right) / \rho\left(\mathbf{r}_{\mathrm{c}}\right)$ is less than 1.0 for shared interactions and greater than 1.0 for closed-shell interactions. The evidence provided for nonmetallic oxides, silicates, and organometallic oxides supports this argument and shows that $G\left(\mathbf{r}_{\mathrm{c}}\right) / \rho\left(\mathbf{r}_{\mathrm{c}}\right)$ actually increases as the bond length decreases and $H\left(\mathbf{r}_{\mathrm{c}}\right)$ decreases.

\section{Closed-Shell O-O Interactions}

Bond paths of maximum ED spanning the $\mathrm{O}-\mathrm{O}$ shared edges between equivalent and quasi-equivalent $\mathrm{MO}_{n}(n>4)$ coordina- tion polyhedra are not uncommon features in the ED distributions of earth materials. ${ }^{23,24,31}$ As the $H\left(\mathbf{r}_{\mathrm{c}}\right)$ values for these interactions are typically small and positive in value, they qualify as closed-shell weakly stabilizing interactions like the $\mathrm{O}-\mathrm{O}$ paths in arsenolite and claudetite I. Despite their relative weakness, the connection made between the directed paths in arsenolite, for example, suggests that the $\mathrm{O}-\mathrm{O}$ bonded interactions together with the As- $\mathrm{O}$ bonded interactions play a small yet important role in determining the structures. $\mathrm{O}-\mathrm{O}$ interactions have also been suggested to play an important role in understanding the distortions of the $\mathrm{Mn}_{2}(\mathrm{CO})_{10}$ molecules in the binuclear carbonyl crystal structure ${ }^{32}$ as well as making a non-negligible contribution to the structure and stability of 

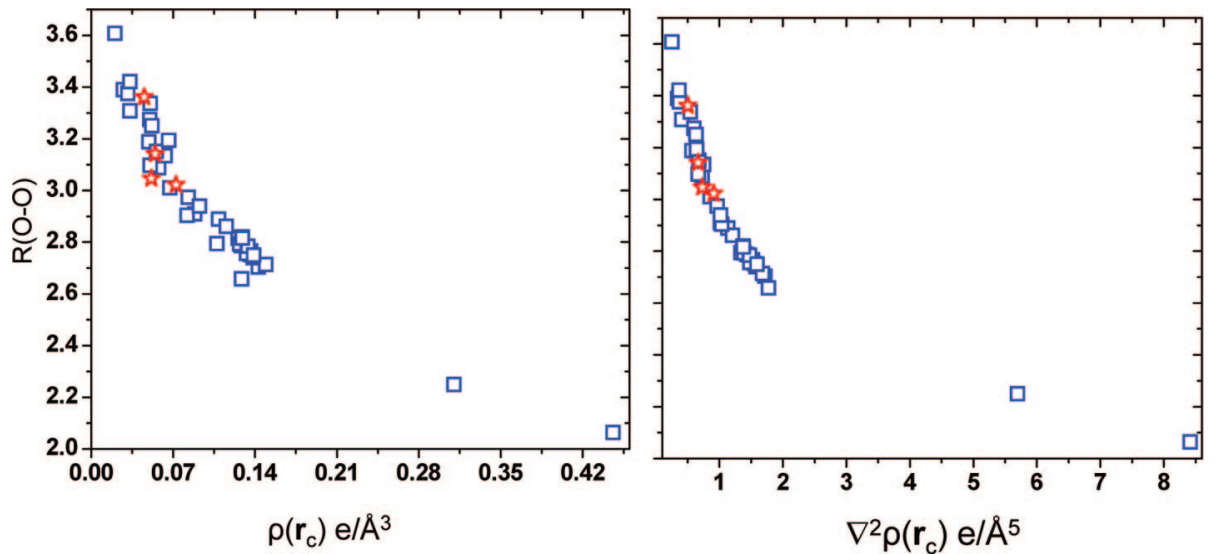

Figure 17. Scatter diagram of $\mathrm{O}-\mathrm{O}$ separations, $R(\mathrm{O}-\mathrm{O})$, for $\mathrm{O}$ atoms connected by bond paths for silicates and arsenolite, claudetite $\mathrm{I}$, and $\mathrm{As} \mathrm{O}_{2}$ plotted with respect to (a) $\rho\left(\mathbf{r}_{\mathrm{c}}\right)$ and (b) $\nabla^{2} \rho\left(\mathbf{r}_{\mathrm{c}}\right)$. The silicates data (ref 23) are plotted as blue squares, and those for arsenolite, claudetite I, and $\mathrm{AsO}_{2}$ data are plotted as red squares.

nucleic acids. ${ }^{33}$ Bond paths are not restricted to $\mathrm{O}$ atoms, but $\mathrm{F}-\mathrm{F}$ bond paths, for example, have been found to be ubiquitous in crowded difluorinated aromatic compounds ${ }^{34}$ where the paths can impart as much as $14 \mathrm{kcal} / \mathrm{mol}$ of local stabilization to the outer regions of the molecules. More recently, $\mathrm{O}-\mathrm{O}$ bond paths reported between the $\mathrm{O}$ atoms in open conformers of the enol forms of $c i s$ - $\beta$-diketones were found to impart $16 \mathrm{kcal} / \mathrm{mol}$ to the total energy of the 1,8-naphthalenediol molecule when optimized at the MP2 level. ${ }^{35}$

As the ED distribution adopts a configuration that results in the lowest energy for a given stationary state, the accumulation of the ED along the $\mathrm{O}-\mathrm{O}$ bond paths relative to one that lacks such paths has been suggested as a means whereby $\mathrm{O}-\mathrm{O}$ interactions serve to locally stabilize a structure. ${ }^{36}$ In explaining the role played by the $\mathrm{O}-\mathrm{O}$ bond paths linking the shared edges of the coordinated polyhedra, it has been suggested that the ED along the bond path spanning the shared edges of the polyhedra in oxides and silicates serves to stabilize the structures locally by shielding the charges on the cations in the adjacent edgesharing polyhedra. ${ }^{23}$ As the $\mathrm{O}-\mathrm{O}$ separations, $R(\mathrm{O}-\mathrm{O})$, for the closed-shell $\mathrm{O}-\mathrm{O}$ interactions reported for oxides and silicates ${ }^{23}$ decrease, the values of $\rho\left(\mathbf{r}_{\mathrm{c}}\right)$ and $\nabla^{2} \rho\left(\mathbf{r}_{\mathrm{c}}\right)$ both increase nonlinearly (Figure 17). The $\mathrm{O}-\mathrm{O}$ bond paths found for the arsenates are relatively few in number with one nonequivalent bond path found for arsenolite, one for claudetite I, and two for $\mathrm{AsO}_{2}$. The $\rho\left(\mathbf{r}_{\mathrm{c}}\right)$ and $\nabla^{2} \rho\left(\mathbf{r}_{\mathrm{c}}\right)$ values for these materials are plotted together with those reported for the silicates and oxides in Figure 17 where it is evident that the properties of the $\mathrm{O}-\mathrm{O}$ interactions in the arsenates are comparable with those reported for the oxides and silicates. As reported for the $\mathrm{O}-\mathrm{O}$ interactions, as the separations between the $\mathrm{F}$ atoms, $R(\mathrm{~F}-\mathrm{F})$, for difluorinated aromatic compounds increase, $\rho\left(\mathbf{r}_{\mathrm{c}}\right), \nabla^{2} \rho\left(\mathbf{r}_{\mathrm{c}}\right)$, and $G\left(\mathbf{r}_{\mathrm{c}}\right)$ each decrease nonlinearly while $V\left(\mathbf{r}_{\mathrm{c}}\right)$ increases nonlinearly such that $H\left(\mathbf{r}_{\mathrm{c}}\right)$ decreases to a minimum values at $R(\mathrm{~F}-\mathrm{F})=2.65 \AA$ and then increases slightly with increasing $R(\mathrm{~F}-\mathrm{F})$. Thus, $G\left(\mathbf{r}_{\mathrm{c}}\right)$ decreases while $V\left(\mathbf{r}_{\mathrm{c}}\right)$ increases and becomes less stabilizing with increasing separation, whereas $H\left(\mathbf{r}_{\mathrm{c}}\right)$ decreases and then increases slightly for F-F separations greater than $2.65 \AA$. $G\left(\mathbf{r}_{\mathrm{c}}\right)$ also decreases and $V\left(\mathbf{r}_{\mathrm{c}}\right)$ decreases nonlinearly for the $\mathrm{O}-\mathrm{O}$ interactions for the oxides and silicates while $H\left(\mathbf{r}_{\mathrm{c}}\right)$ increases in value.

\section{Summary}

van der Waals forces are generally believed to be nondirectional and to arise by dint of weak electronic coupling between atoms and molecules other than those that lead to chemical binding. ${ }^{37}$ But, the orthorhombic layered structure adopted by the $\mathrm{Cl}_{2}$ molecules in solid chlorine belies this belief in that a critical examination of the structure ${ }^{38}$ found that the LennardJones 6-12 isotropic intermolecular potential (an expression originally proposed for gases and liquids, where the interactions average to an isotropic mean) not only utterly fails to predict the correct tilt angle of the $\mathrm{Cl}_{2}$ molecules in the structure but also fails to account for the observed greater stability of the orthorhombic structure relative to the cubic one. But, as we have seen, the packing and layer structure adopted by the $\mathrm{Cl}_{2}$ molecules can be understood by considering parallel sets of mainstay directed van der Waals $\mathrm{Cl}-\mathrm{Cl}$ bond paths that involve base and acid domains of $\mathrm{ED}^{6}$ where the directed character of the van der Waals bonded interactions conforms with theoretical studies $^{2,3}$ that indicate that there is little difference between van der Waals and covalent binding.

The molecular structures adopted by the arsenates examined in this report can likewise be understood in terms of parallel sets of directed bond paths, mainstays that play a determinate role, particularly in the case of arsenolite, in the formation of the periodic structures adopted by the molecular solids. The molecular structure adopted by the antimony trioxide, senarmontite, can also be understood in terms of mainstay directed acid-base $\mathrm{Sb}-\mathrm{O}$ van der Waals interactions. ${ }^{25}$ In addition, calculations of the ED, the bond critical point properties, and the Laplacian for several arsenic sulfides (realgar, AsS, pararelgar, AsS, alacranite, $\mathrm{AsS}, \alpha$ - and $\beta$-dimorphite, $\mathrm{As}_{4} \mathrm{~S}_{3}$, and uzonite, $\left.\mathrm{As}_{4} \mathrm{~S}_{5}\right)^{39}$ provide further evidence for the argument that van der Waals forces are directional. Despite the directionality of the bond paths, a mapping of the barycenters for the arsenic sulfide molecules shows that they are approximately cubic closepacked in their spatial array in the crystals, a result that demonstrates that a close-packed array of molecules can form when they are linked by directed van der Waals bonded interactions.

Finally, in a comprehensive and careful review of the structures and properties of the fullerenes, Dresselhaus et al. ${ }^{40}$ observed that the bonded interactions in graphite and the solid fullerene $\mathrm{C}_{60}$ are strikingly similar where the $\mathrm{C}$ layers of graphite and the $\mathrm{C}_{60}$ molecules of fullerene are weakly bonded together by van der Waals interactions. Recent calculations completed in our laboratories for graphite show that well-developed intermolecular $\mathrm{C}-\mathrm{C}$ bond paths exist between the layers, a result that indicates that the layers are bound by the directed 
intermolecular $\mathrm{C}-\mathrm{C}$ bond paths. At room temperature, the evidence indicates that the molecules in solid $\mathrm{C}_{60}$ exhibit complete orientational disorder about their cubic sites, but at a temperature below $\sim 225 \mathrm{~K}$, they exhibit orientational order and are aligned with the double-bond electron-rich (Lewis base) domain of one molecule positioned next an electron-poor (Lewis acid) domain of an adjacent molecule. ${ }^{41}$ Given the similarities of the bonded interactions in graphite and solid $\mathrm{C}_{60}$, it is tempting to speculate whether or not the alignment of the double-bond electron-rich (Lewis base) and electron-poor (Lewis base) domains between the adjacent $\mathrm{C}_{60}$ molecules correspond with the alignment of the acid-base domains in solid chlorine. It is also tempting to speculate whether or not the domains are connected by $\mathrm{C}-\mathrm{C}$ acid-base directed bond paths. It is also noteworthy that the molecules in solid $\mathrm{C}_{70}$ adopt a similar alignment of acid-base domains at low temperatures. As such, the question arises whether the molecules in the solid are likewise connected by directed $\mathrm{C}-\mathrm{C}$ bond paths, serving as Fischer lock and key mainstays for the hexagonal close-packed structure. $^{42}$

Acknowledgment. The National Science Foundation and the U.S. Department of Energy are thanked for supporting this study with Grants EAR-0609885 (N.L.R. and G.V.G.), EAR-0609906 (R.T.D.), and DE-FG02-97ER14751 (D.F.C.). P.M.D. acknowledges the support of the National Science Foundation (EAR0545166; OCE-052667) and the Department of Energy (FG0200ER15112). K.M.R. acknowledges a Grant from the U.S. Department of Energy (DOE), Office of Basic Energy Sciences, Geosciences Division and computational facilities and support from the Environmental Molecular Sciences Laboratory (EMSL) at the Pacific Northwest National Laboratory (PNNL). The computations were performed in part at the EMSL at PNNL. The EMSL is a national scientific user facility sponsored by the U.S. DOE Office of Biological and Environmental Research. PNNL is operated by Battelle for the DOE under contract DEAC06-76RLO 1830. G.V.G. takes great pleasure in thanking Professor Richard F. W. Bader of the Chemistry Department of MacMasters University for his encouragement, invaluable advice, and suggestions in the preparation of the manuscript. We are also indebted to Professor David Vaughan of the University of Manchester and two anonymous reviewers who provided careful reviews of the manuscript and made a number of important suggestions that improved the manuscript. Professor Vladimir G. Tsirelson of the Mendeleev University of Chemical Technology in Moscow is thanked for kindly giving us permission to use Figure 1 from his paper on bonded interactions in solid molecular chlorine in the preparation of our manuscript. Finally, any opinions, findings, and conclusions or recommendations expressed in this paper are those of the authors and do not necessarily reflect the views of the National Science Foundation or the Department of Energy.

\section{References and Notes}

(1) Atkins, P. W. Quanta: A Handbook of Concepts; Oxford Clarendon Press: Oxford, U.K., 1974.
(2) Feynman, R. P. Phys. Rev. 1939, 56, 340.

(3) Slater, J. C. J. Chem. Phys. 1972, 57, 2389. 6788.

(4) Bader, R. F. W.; MacDougall, P. J. J. Am. Chem. Soc. 1985, 107,

(5) Bader, R. F. W.; Hernandez-Trujillo, J.; Cortes-Guzman, F. J. Comput. Chem. 2007, 28, 4.

(6) Tsirelson, V. G.; Zou, P. F.; Tang, T. H.; Bader, R. F. W. Acta Crystallogr., Sect. A 1995, 51, 143.

(7) Yamasaki, K. J. Phys. Soc. Jpn. 1962, 1262.

(8) Saunders, V. R.; Dovesi, R.; Roetti, C.; Causa, M.; Harrison, N. M.; Orlando, R.; Apra, E. CRYSTAL98 User's Manual; University of Torino: Torino, Italy, 1998.

(9) Gatti, C. TOPOND96 User's Manual; CNR-CSRSRC: Milano, Italy, 1997.

(10) Humphrey, W.; Dalke, A.; Schulten, K. J. Mol. Graphics 1996, 14,33 .

(11) Ballirano, P.; Maras, A. Z. Kristallogr.-New Cryst. Struct. 2002, 217,177 .

(12) Pertlik, F. Monatsh. Chem. 1975, 106, 755.

(13) Lezal, D.; Konak, K. J. Non-Cryst. Solids 1995, 193, 187.

(14) Pokrovski, G.; Gout, R.; Schott, J.; Zotov, A.; Harrichoury, J. C. Geochim. Cosmochim. Acta 1996, 60, 737.

(15) Becker, K. A.; Karge, H.; Stranski, I. N. Z. Phys. Chem. 1965, 44, 1 .

(16) Grzechnik, A. J. Solid State Chem. 1999, 144, 416.

(17) Puselj, M.; Ban, Z.; Grdenic, D. Z. Anorg. Allg. Chem. 1977, 437, 289.

(18) Bonazzi, P.; Bindi, L. Z. Kristallogr. 2008, 223, 132.

(19) Cremer, D.; Kraka, E. Angew. Chem., Int. Ed. Engl. 1984, 23, 627.

(20) Cremer, D.; Kraka, E. Croat. Chem. Acta 1984, 57, 1259.

(21) Bader, R. F. W.; Essen, H. J. Chem. Phys. 1984, 80, 1943.

(22) Espinosa, E.; Alkorta, I.; Elguero, J.; Molins, E. J. Chem. Phys. 2002, 117, 5529.

(23) Gibbs, G. V.; Downs, R. T.; Cox, D. F.; Ross, N. L.; Boisen, M. B.; Rosso, K. M. J. Phys. Chem. A 2008, 112, 3693.

(24) Luana, V.; Costales, A.; Mori-Sanchez, P.; Pendas, A. M. J. Phys. Chem. B 2003, 107, 4912 .

(25) Whitten, A. E.; Dittrich, B.; Spackman, M. A.; Turner, P.; Brown, T. C. Dalton Trans. 2004, 23.

(26) Shannon, R. D.; Prewitt, C. T. Acta Crystallogr., Sect. B 1969, 25 , 925.

(27) Jones, P. G.; Beesk, W.; Sheldrick, G. M.; Schwartzmann, E. Acta Crystallogr., Sect. B 1980, 36, 439.

(28) Jansen, M. Z. Anorg. Allg. Chem. 1978, 441, 5.

(29) Gibbs, G. V.; Downs, R. T.; Cox, D. F.; Rosso, K. M.; Ross, N. L.; Kirfel, A.; Lippmann, T.; Morgenroth, W.; Crawford, T. D. J. Phys. Chem. A 2008, 112, 8811.

(30) Bone, R. G. A.; Bader, R. F. W. J. Phys. Chem. 1996, 100, 10892.

(31) Gibbs, G. V.; Boisen, M. B.; Rosso, K. M.; Teter, D. M.; Bukowinski, M. S. T. J. Phys. Chem. B 2000, 104, 10534.

(32) Bianchi, R.; Gervasio, G.; Marabello, D. Inorg. Chem. 2000, 39, 2360

(33) Matta, C. F.; Castillo, N.; Boyd, R. J. J. Phys. Chem. B 2006, 110, 563.

(34) Matta, C. F.; Castillo, N.; Boyd, R. J. J. Phys. Chem. A 2005, 109, 3669.

(35) Pakiari, A. H.; Eskandari, K. J. Mol. Struct. (THEOCHEM) 2007, 806,1 .

(36) Gatti, C. Z. Kristallogr. 2005, 220, 399.

(37) Kitaigorodskii, A. I. Molecular Crystals and Molecules; Academic Press: New York, 1973; Vol. 29.

(38) Hillier, I. H.; Rice, S. A. J. Chem. Phys. 1967, 46, 3881

(39) Gibbs, G. V.; Wallace, A. F.; Cox, D. F.; Downs, R. T.; Rosso,

K. M. To be submitted for publication.

(40) Dresselhaus, M. S.; Dresselhaus, G.; Eklund, P. C. J. Mater. Res. 1993, 8, 2054.

(41) Fischer, J. E.; Heiney, P. A. J. Phys. Chem. Solids 1993, 54, 1725.

(42) Dorset, D. L. J. Phys. Chem. 1995, 99, 16748.

JP807666B 